UNIVERSIDADE DE SÃO PAULO

ESCOLA DE EDUCAÇÃO FÍSICA E ESPORTE

INFLUÊNCIA DA EXPERIÊNCIA EM

TREINAMENTO DE FORÇA NA POTENCIALIZAÇÃO

DA FORÇA EXPLOSIVA

Mauro Alexandre Benites Batista

SÃO PAULO

2005 


\section{INFLUÊNCIA DA EXPERIÊNCIA EM \\ TREINAMENTO DE FORÇA NA POTENCIALIZAÇÃO \\ DA FORÇA EXPLOSIVA}

MAURO ALEXANDRE BENITES BATISTA

Dissertação apresentada à Escola de Educação Física e Esporte da Universidade de São Paulo, como requisito parcial para obtenção do grau de Mestre em Educação Física. 


\section{Batista, Mauro Alexandre Benites}

Influência da experiência em treinamento de força na potencialização da força explosiva / Mauro Alexandre Benites Batista. - Sào Paulo : [s.n.], 2005.

$$
\text { xi, 55p. }
$$

Dissertação (Mestrado) - Escola de Educação Física e Esporte da Universidade de Sào Paulo.

Orientador: Prof. Dr. Valmor Alberto Augusto Tricoli.

1. Treinamento esportivo I. Título. 


\section{AGRADECIMENTOS}

Gostaria de agradecer à minha familia pelo incentivo, à minha esposa pela paciência, às pessoas que participaram como sujeitos desse estudo pela colaboração, aos meus colegas de grupo de estudo pela valiosa contribuição, ao professor Dr. Carlos Ugrinowitsch pelo seu empenho em me ensinar algo e, finalmente, ao meu orientador professor Dr. Valmor Tricoli por ter me dado uma oportunidade desejada por muitos, pela enorme paciência e disponibilidade em todos momentos que o solicitei durante estes anos. 
AGRADECIMENTOS ……............................................................. ii

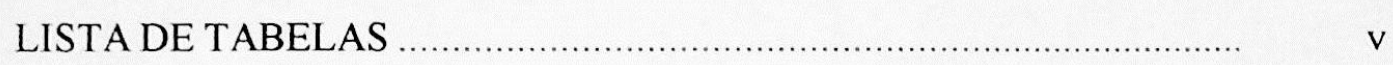

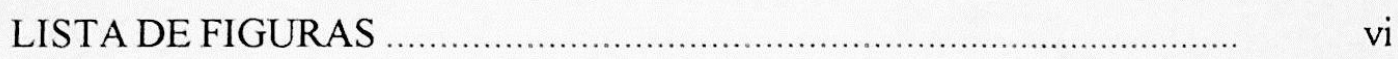

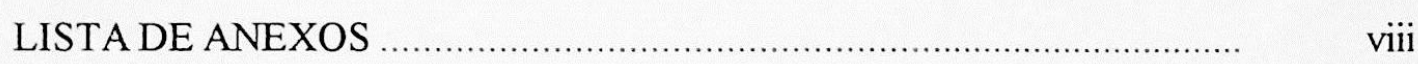

LISTA DE ABREVIAÇÕES .......................................................... ix

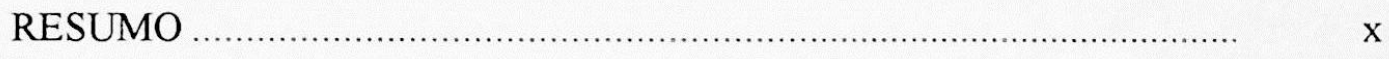

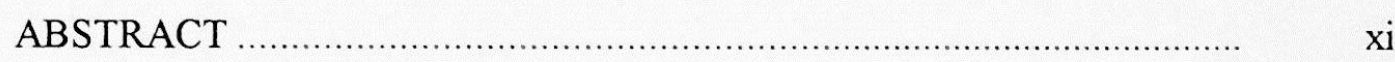

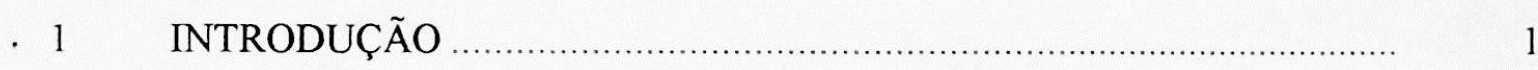

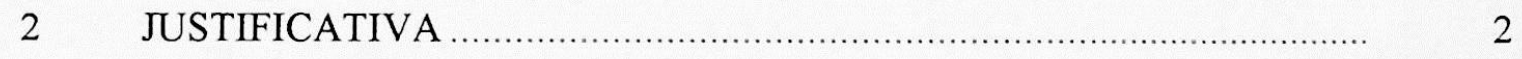

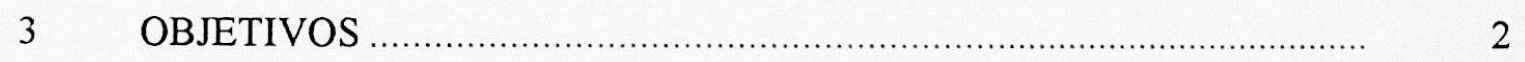

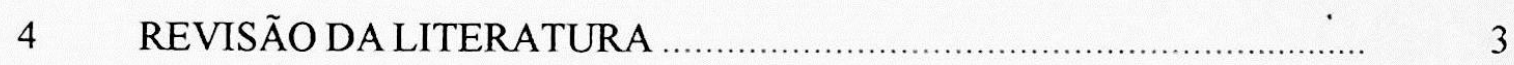

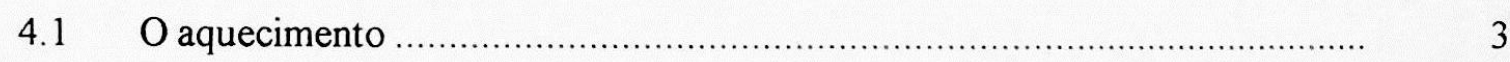

4.2 Mecanismos fisiológicos responsáveis pela potencialização …………….... 4

4.3 Características das atividades estimuladoras da potencialização ................. 9

4.4 Avaliação da manifestação da potencialização ………………………........... 11

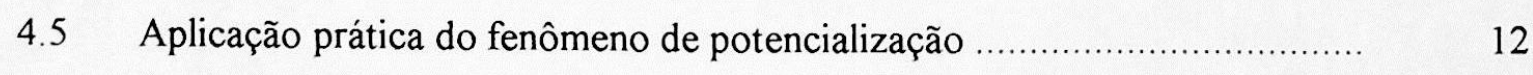

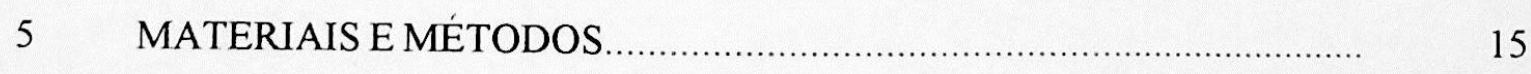

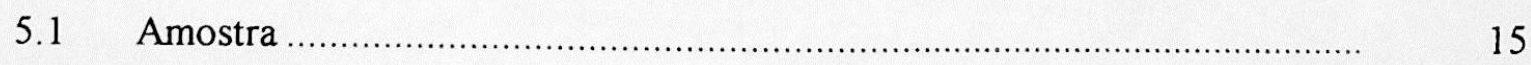

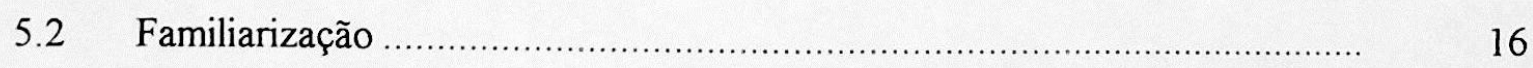

5.3 Desenho experimental e procedimentos do estudo ……................................. 18 


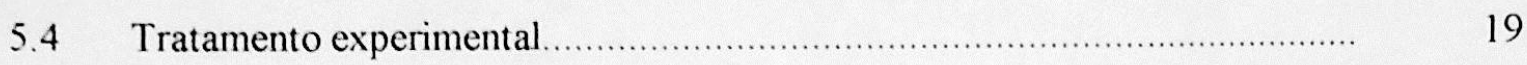

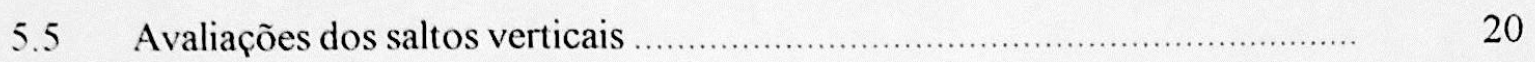

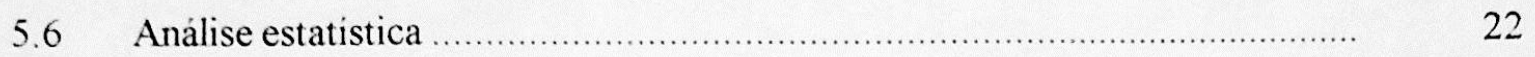

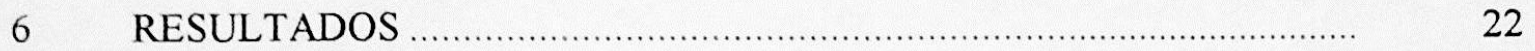

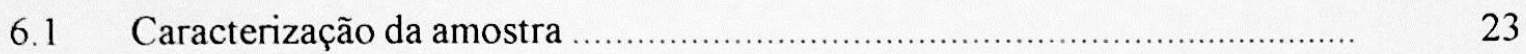

6.2 Comparação da força dinâmica máxima (1RM) entre os grupos ................ 23

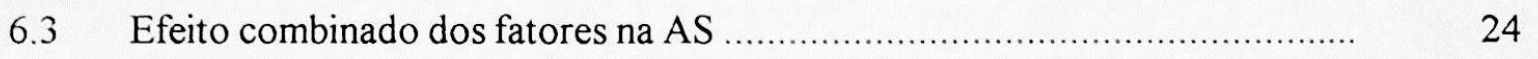

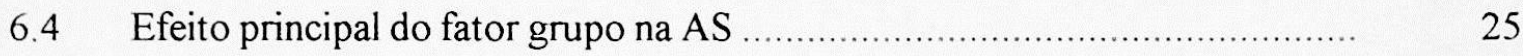

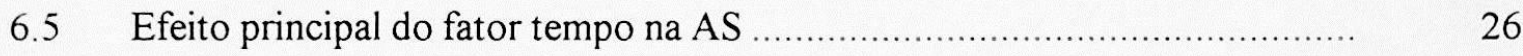

6.6 Efeito principal do fator tratamento na AS ............................................... 27

6.7 Efeito combinado dos fatores na TDF média ....................................... 28

6.8 Efeito principal do fator grupo na TDF média ......................................... 29

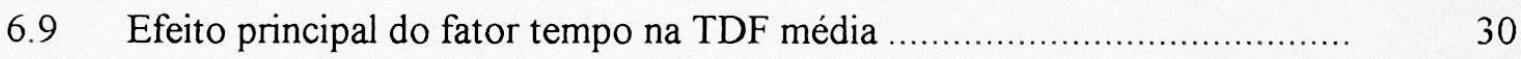

6.10 Efeito principal do fator tratamento na TDF média .............................. 30

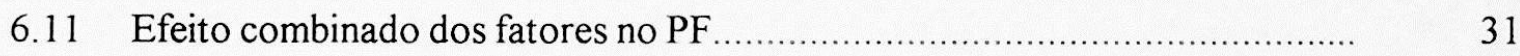

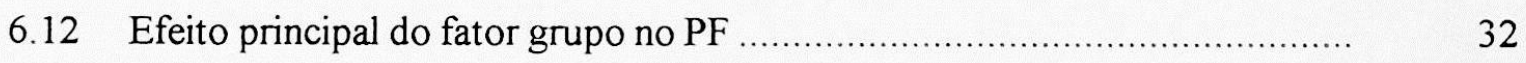

6.13 Efeito principal do fator tempo no PF …............................................ 33

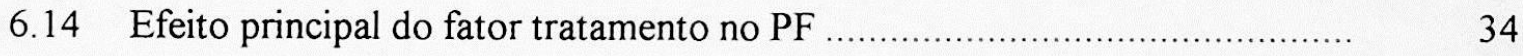

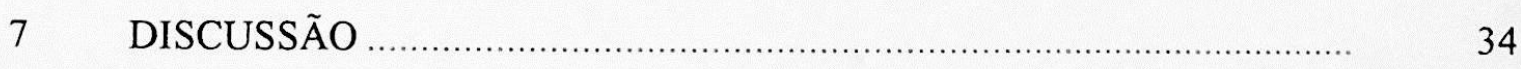

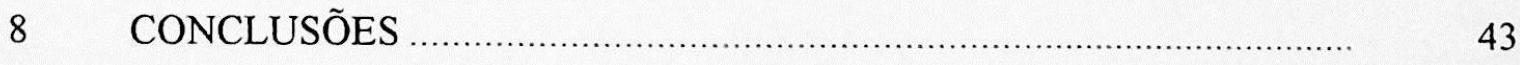

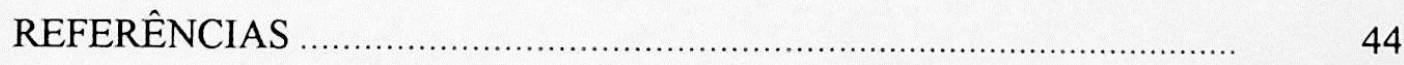

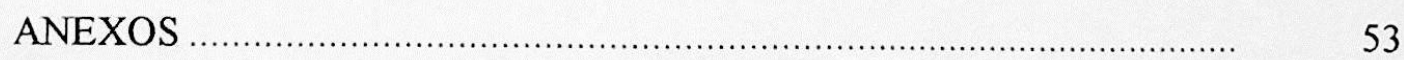




\section{LISTA DE TABELAS}

Página

TABELA 1- Médias e desvios-padrão da idade, peso e estatura, dos sujeitos de cada grupo 


\section{LISTA DE FIGURAS}

Página

FIGURA 1 - Comparação, entre grupos, da força dinâmica máxima através do teste de 1RM no exercício leg press

FIGURA 2 - Efeito combinado dos fatores, na AS, analisando o salto de melhor desempenho

FIGURA 3 - Efeito combinado dos fatores, na AS, analisando a média de três saltos

FIGURA 4 - Efeito principal do fator grupo, na AS, analisando a média de três saltos e o salto de melhor desempenho

FIGURA 5 - $\quad$ Efeito principal do fator tempo, na AS, analisando a média de 3 saltos e o salto de melhor desempenho

FIGURA 6 - Efeito principal do fator tratamento, na AS, analisando a média de três saltos e o salto de melhor desempenho

FIGURA 7 - Efeito combinado dos fatores, na TDF média, analisando o salto de melhor desempenho

FIGURA 8 - Efeito combinado dos fatores, na TDF média, analisando a média de três saltos

FIGURA 9 - Efeito principal do fator grupo, na TDF média, analisando a média de três saltos ou o salto de melhor desempenho

FIGURA 10 - Efeito principal do fator tempo, na TDF média, analisando a média de três saltos e o salto de melhor desempenho

FIGURA 11- Efeito principal do fator tratamento, na TDF média, analisando a média de três saltos e o salto de melhor desempenho

FIGURA 12 - Efeito combinado dos fatores, no PF, analisando a média de três saltos

FIGURA 13 - Efeito combinado dos fatores, no PF, analisando o salto de melhor desempenho 
FIGURA 14 - Efeito principal do fator grupo, no PF, analisando a média de très saltos e o salto de melhor desempenho

FIGURA 15 - Efeito principal do fator tempo, no PF, analisando a média de três saltos e o salto de melhor desempenho

FIGURA 16 - Efeito principal do fator tratamento, no PF, analisando a média de três saltos e o salto de melhor desempenho 


\section{LISTA DE ANEXOS}

Página

ANEXO I - Informação pessoal e questionário de atividade fisica 53

ANEXO II - Consentimento Informado 54 ANEXO III - Foto do aparelho leg press 


\section{LISTA DE ABREVIAÇÕES}

$\begin{array}{ll}\text { ICVIM 5s } & \text { - Uma CVIM de cinco segundos de duração } \\ \text { IRM } & \text { - Uma repetição máxima } \\ \text { 3CVIM 5s } & \text { - Três CVIM de cinco segundos de duração } \\ \text { 5RM } & \text { - Cinco repetições máximas } \\ \text { AS } & \text { - Altura do salto } \\ \text { CVIM } & \text { - Contração voluntária isométrica máxima } \\ \text { CVSM } & \text { - Contrações voluntárias submáxima } \\ \text { EMG } & \text { - Eletromiografia } \\ \text { FDM } & \text { - Força dinâmica máxima } \\ \text { Miosina RCL } & \text { - Miosina regulatória de cadeia leve } \\ \text { PF } & \text { - Pico de força } \\ \text { PPA } & \text { - Potencialização pós-ativação } \\ \text { PPT } & \text { - Potencialização pós-tetânica } \\ \text { SVCM } & \text { - Saltos verticais máximos com contramovimento } \\ \text { TDF } & \text { - Taxa de desenvolvimento de força } \\ \text { TDF média } & \text { Tádia de desenvolvimento de força }\end{array}$


RESUMO

\title{
INFLUÊNCIA DA EXPERIÊNCIA EM TREINAMENTO DE FORÇA NA POTENCIALIZAÇÃO DA FORÇA EXPLOSIVA
}

\author{
Autor: MAURO ALEXANDRE BENITES BATISTA \\ Orientador: PROF. DR. VALMOR A. A. TRICOLI
}

O objetivo desse estudo foi verificar se o tipo de experiência em treinamento de força influencia na potencialização do salto vertical com contramovimento (SVCM). Vinte e sete sujeitos foram divididos em três grupos: atletas de modalidades esportivas de potência $(\mathrm{ATL}=10)$, treinados em força para aumento de massa muscular $(\mathrm{TRF}=7)$ e fisicamente ativos $(\mathrm{FIS}=10)$. Todos foram submetidos, ou não (controle), a dois protocolos de aquecimento, que eram compostos por uma ou três contrações voluntárias isométricas máximas de cinco segundos de duração (1CVIM 5s ou 3CVIM 5s), no exercício leg-press. A eficiência dos exercícios de força como aquecimento foi testada na altura (AS), taxa média de desenvolvimento de força (TDF média) e pico de força (PF), produzidos no SVCM. Não foram encontradas alterações significantes nestas variáveis, em resposta aos diferentes protocolos de aquecimento, em nenhum dos grupos testados. O resultado foi semelhante analisando o comportamento das variáveis através da média de três saltos $(F=0,26 ; p=0,97)$ ou através do salto de melhor desempenho $(F=0,51 ; p=0,84)$. Conclui-se que a potencialização do salto vertical, induzida por exercícios de força, não é um fenômeno dependente do tipo de experiência do sujeito em treinamento de força.

Palavras-chave: Aquecimento, contrações voluntárias isométricas máximas, salto vertical. 


\begin{abstract}
THE INFLUENCE OF STRENGTH TRAINING EXPERIENCE ON EXPLOSIVE STRENGTH POTENTIATION
\end{abstract}

\author{
Author: MAURO ALEXANDRE BENITES BATISTA \\ Adviser: PROF. DR. VALMOR A. A. TRICOLI
}

The aim of this study was to verify if different strength training experience could modulate vertical jump potentiation. Twenty seven subjects were divided in three groups: track and field athletes $(\mathrm{ATL}=10)$, subjects with experience in strength training designed to improve muscle hypertrophy $(\mathrm{TRF}=7)$, and physically active subjects (FIS=10). All groups performed two different warm-up protocols, which were composed, or not (control), by one or three maximum voluntary isometric contractions of five seconds duration (1MVIC $5 \mathrm{~s}$ or 3 MVIC 5s), in the leg-press exercise. Countermovement vertical jump (CMJ) performance was used to assess the effectiveness of the strength exercise to induce potentiation. More specifically, alterations in maximal height, average rate of force development and peak power produced during $\mathrm{CMJ}$ were evaluated. It was not found statistically significant difference in these variables in response to the warm-up protocols (3MVIC, 1MVIC or control). These results were similar when assessed through the mean of three jumps $(F=0,26 ; p=0,97)$ or through the best jump performance $(F=0,51 ; p=0,84)$. We conclude that vertical jump potentiation is not dependent of the subject's strength training experience.

KeyWords: Warm-up, maximal voluntary isometric contractions, vertical jump. 


\section{INTRODUCÃO}

É bastante comum no meio esportivo a realização de exercícios preparatórios, conhecidos como aquecimento, antes do início do treinamento ou competição (BISHOP, 2003a, 2003b; VERKHOSHANSKY \& SIFF, 1993; YOUNG \& BEHM, 2003). Acredita-se que o aquecimento previne a ocorrência de lesões e que pode aprimorar o desempenho. Tradicionalmente, o aquecimento é composto por uma atividade aeróbia de baixa intensidade e curta duração, exercícios de alongamento e movimentações específicas da modalidade. Este protocolo de aquecimento é praticado, indistintamente, por atletas de diferentes modalidades esportivas (BISHOP, 2003a, 2003b; YOUNG \& BEHM, 2003). Entretanto, tem sido sugerido que atletas de modalidades esportivas de potência incluam exercícios de força, em sua rotina de aquecimento, em complementação aos exercícios convencionais (GÜLLICH \& SCHMIDTBLEICHER, 1996; VERKHOSHANSKY \& SIFF, 1993). Alguns estudos demonstraram que exercícios dependentes da manifestação da força explosiva podem ser potencializados, ou seja, ser beneficiados com a melhora aguda do desempenho quando, no aquecimento, são realizados exercícios de força (GOURGOULIS, ANGGELOUSSIS, KASIMATIS, MAVROMATIS \& GARAS, 2003; GÜLLICH \& SCHMIDTBLEICHER, 1996). Outros estudos, no entanto, colocam em dúvida a validade desse procedimento, uma vez que seus resultados não apontaram qualquer beneficio de tal prática (GOSSEN \& SALE, 2000; HRYSOMALLIS \& KIDGELL, 2001; KOCH, O'BRYANT, STONE, SANBORN, PROULX, HRUBY, SHANNONHOUSE, BOROS \& STONE, 2003; RADCLIFFE \& RADCLIFFE, 1996).

Parece que a potencialização da força explosiva, provocada pela realização prévia de exercícios de força, é um fenômeno condicionado a determinados fatores. Segundo GÜLLICH e SCHMIDTBLEICHER (1996), ela depende das características dos exercícios de força utilizados no aquecimento. Outros estudos sugerem que a potencialização depende do estado de treinamento dos sujeitos. No estudo de DUTHIE, YOUNG e AITKEN (2002) sujeitos com melhor desempenho no teste de força dinâmica máxima (3RM) potencializaram o pico de força produzido durante o salto vertical. GOURGOULIS et al. (2003) verificaram que a potencialização da altura do salto vertical foi maior em indivíduos com maior nível de força dinâmica máxima (1RM). Contudo, isso não se confirmou nos estudos de HYRSOMALLIS e 
KIDGEL (2001) e SCOTT e DOCHERTY (2004) nos quais se estudou o efeito de potencialização em individuos experientes em treinamento de força.

Foi ainda sugerido que o efeito de potencialização é mais pronunciado em atletas envolvidos em modalidades de potência. No entanto, os estudos a esse respeito também são contraditórios. Outros fatores, como o tipo de exercício utilizado no aquecimento, sua intensidade e duração, podem interferir na manifestação da potencialização (GÜLLICH \& SCHMIDTBLEICHER, 1996; RADCLIFFE \& RADCLIFFE, 1996).

Parece que o aquecimento direcionado a atletas especialistas em provas de potência deve ser diferente do realizado por atletas de outras provas. A realização de exercícios de força, no aquecimento, pode ser interessante para estes atletas. Contudo, ainda há muita dúvida se todos atletas envolvidos nesse tipo de prova podem se beneficiar utilizando exercícios de força no aquecimento. Também não se sabe ao certo quais exercícios de força são realmente efetivos em desencadear melhoras agudas no desempenho. Para sugerir a inclusão de exercícios de força no aquecimento, é preciso conhecer as respostas para essas questões. Desta forma, verificar a influência da experiência em treinamento de força e do volume de exercícios utilizados para induzir a potencialização da força explosiva pode ser importante para melhor orientar o conteúdo do aquecimento.

\section{JUSTIFICATIVA}

Atletas praticantes de modalidades esportivas de potência têm sido orientados a incluir exercícios de força em suas rotinas de aquecimento. Contudo, os estudos que investigaram a efetividade deste procedimento, em melhorar o desempenho, são contrastantes. É possível que a resposta aos exercícios de força no aquecimento seja modulada pela experiência do indivíduo em treinamento de força. É fundamental conhecer quais condições tornam os indivíduos aptos a se beneficiar dessa estratégia, para que se possa recomendá-la.

\section{OBJETIVOS}

- Verificar se o aquecimento com exercícios de força potencializa o desempenho do salto vertical com contramovimento, em indivíduos com diferentes experiências em treinamento de força; 
- Verificar se a potencialização do salto vertical com contramovimento, em indivíduos com diferentes experièncias em treinamento de força, depende do volume de exercicios de força realizados no aquecimento.

\section{REVISÃO DA LITERATURA}

\subsection{O aquecimento}

A realização de exercícios de aquecimento é uma prática bastante difundida entre atletas e treinadores de alto nivel e também entre pessoas que praticam atividade fisica apenas por lazer e para melhorar o condicionamento. A principal razão para a realização dos exercícios de aquecimento se apóia na crença de que, através deles, é possível diminuir a incidência de lesões. Também possui bastante força o argumento de que o aquecimento pode melhorar o desempenho da atividade que se seguirá. Durante uma rotina de aquecimento convencional são realizados basicamente três tipos de exercícios. Um exercício com componente aeróbio, como correr, pedalar ou nadar, exercícios de alongamento e movimentações típicas da modalidade com intensidade diminuida. Este protocolo de aquecimento é praticado, indistintamente, por atletas de diferentes modalidades esportivas, o que pode ser inadequado. Uma recente revisão a respeito do assunto mostra que os exercícios com componente aeróbio podem melhorar o desempenho, porém, apenas em alguns tipos de atividades motoras (BISHOP, 2003a, 2003b). Por exemplo, a corrida utilizada como exercício de aquecimento, induz um aumento do consumo de oxigênio no início da atividade subseqüente. Como conseqüência, esse aumento faz diminuir a quantidade de trabalho realizado em déficit de oxigênio no início do exercício principal, poupando energia proveniente da via anaeróbia, que pode ser utilizada mais adiante na atividade, o que implicaria em uma melhora do desempenho. No entanto, atividades de curta duração e alta intensidade como as que predominam em modalidades esportivas de força e potencia não se beneficiam desse efeito, já que, nessas atividades, o desempenho não depende da oferta de oxigênio aos músculos (BISHOP, 2003a).

Contudo, um outro efeito dos exercícios com componente aeróbio, o aumento da temperatura muscular, pode ser benéfico aos exercícios de força e potência. $\mathrm{O}$ aumento da temperatura muscular, por meio de diatermia, diminui a resistência passiva articular. $\mathrm{O}$ 
"stiffness" das fibras musculares, durante a contração, também diminui em função do aumento da temperatura muscular. Contudo, essas alterações repercutem em melhoras muito pequenas no desempenho da contração muscular (BISHOP, 2003a).

Foi demonstrado que o aumento da temperatura muscular melhora a velocidade de transmissão dos impulsos nervosos, o que pode contribuir para um melhor desempenho nos exercicios de força e potência (STEWART, MACALUSO \& DE VITO, 2003). No entanto, poucos estudos comprovaram esse beneficio do aumento da temperatura muscular na velocidade de condução nervosa (BISHOP, 2003a, 2003b).

O beneficio do uso de exercícios de alongamento, como conteúdo do aquecimento para tarefas que exijam esforços explosivos, também é controverso. Alguns estudos demonstraram que o alongamento melhora o desempenho nesse tipo de atividade. Por outro lado, outros estudos apontam uma redução significante na produção de força e potência dos músculos submetidos ao alongamento, o que tem levado alguns pesquisadores a recomendar a exclusão desse tipo de exercício da rotina de aquecimento para atividades que requerem esforços desta natureza (CORNWELL, NELSON, HEISE \& SIDWAY, 2001; FLETCHER \& JONES, 2004; YOUNG \& BEHM, 2003).

Como se pode observar, os exercícios de aquecimento convencionais podem ser ineficazes e até prejudiciais para atletas de provas de potência. Contudo, tais atletas podem se beneficiar de uma outra forma de aquecimento que inclui exercícios de força. Em alguns estudos, onde se utilizou exercícios de força no aquecimento, foram demonstradas importantes melhoras em atividades como saltos, arremessos e também na velocidade de movimentos cíclicos. Esse aumento no desempenho, provocado pelo aquecimento com exercícios de força, tem sido referido de forma generalizada como potencialização (RASSIER \& MACINTOSH, 2000; SALE, 2002). A potencialização parece ser produzida por mecanismos fisiológicos desencadeados no músculo e também no sistema nervosos central. Explicações detalhadas sobre o assunto serão dadas na seção seguinte.

\subsection{Mecanismos fisiológicos responsáveis pela potencialização}

O mecanismo fisiológico apontado como o principal causador da potencialização é a fosforilação da miosina regulatória de cadeia leve (RCL), um evento molecular. Segundo RASSIER e MACINTOSH (2000), a incorporação de fosfato, por parte da miosina RCL, 
parece produzir uma alteração na conformação das pontes cruzadas, que coloca as cabeças globulares numa posição mais próxima dos filamentos finos de actina. Conforme os mesmos autores, essa aproximação, provocada pela fosforilação da miosina RCL, aumenta a probabilidade de interação entre as proteinas contráteis

A fosforilação da miosina RCL é mediada pela enzima quinase da miosina RCL. Já a defosforilação da miosina RCL, se deve à ação da fosfatase da miosina RCL. A ativação da quinase da miosina RCL é feita pelo complexo cálcio/calmodulina que, por sua vez, é formado quando o cálcio $\left(\mathrm{Ca}^{2+}\right)$ é liberado pelo retículo sarcoplasmático (RS). Aumentos na atividade da quinase, ou diminuições na atividade da fosfatase modulam a fosforilação da miosina RCL. Acredita-se que o $\mathrm{Ca}^{2+}$ tenha um papel importante na potencialização. Alguns autores defendem que a atividade prévia pode induzir uma maior liberação de $\mathrm{Ca}^{2+}$ pelo retículo sarcoplasmático (RS), o que leva a um aumento de sua concentração no sarcoplasma (RASSIER \& MACINTOSH, 2000; SALE, 2002). Essa maior concentração de $\mathrm{Ca}^{2+}$ pode implicar num maior desenvolvimento de tensão, de duas maneiras. Primeiro, através do aumento na formação do complexo $\mathrm{Ca}^{2+} /$ calmodulina, que em seqüência aumentaria a ativação da quinase da miosina RCL e indiretamente a fosforilação da miosina RCL. Segundo, o aumento do $\mathrm{Ca}^{2}$ sarcoplasmático pode resultar numa maior interação desse com a troponina, provocando uma maior liberação de sítios de actina para conexão das pontes cruzadas de miosina. Contudo, a importância do papel do $\mathrm{Ca}^{2+}$ na potencialização tem sido questionada em razão de os maiores níveis de fosforilação da miosina RCL serem observados quando $\mathrm{Ca}^{2+}$ encontra-se em baixas concentrações no sarcoplasma. Assim, ao invés de um papel principal do $\mathrm{Ca}^{2+}$ na potencialização, tem sido atribuído à ele um papel apenas regulador da mesma (SALE, 2002).

Uma maneira através da qual a fosforilação da miosina RCL pode produzir potencialização da força é alterando o ciclo das pontes cruzadas. Mais precisamente, a fosforização miosina RCL induz alterações na fase de desenvolvimento de tensão do ciclo das pontes cruzadas. A fase de desenvolvimento de tensão do ciclo das pontes cruzadas é compreendida por dois momentos. Em um dos momentos acontece a transição das pontes cruzadas do estado de ligação fraca para o estado de ligação forte. No outro, a transição é reversa, ou seja, as pontes cruzadas passam do estado de ligação forte para o estado de ligação fraca. SWEENEY e STULL (1990) verificaram que a fosforilação da miosina RCL provoca um aumento na taxa de transição do estado de ligação fraca para o forte. Por outro lado, 
KERRICK, POTTER e HOAR (1990) verificaram uma diminuição na taxa de transição reversa, ou seja, na passagem das pontes cruzadas do estado de ligação forte para o estado de ligação fraca, embora nenhuma alteração tenha sido notada nessa fase, no estudo de SWEENEY e STULL (1990). O aumento na taxa de transição do estado de ligação fraca para o forte implica no fato de as pontes cruzadas ficarem menos tempo no estado em que geram pouca tensão e em um início mais rápido da fase de desenvolvimento de alto nível de tensão. Ao contrário, quando a taxa de transição do estado de ligação forte para o fraco diminui, significa que as pontes cruzadas ficam mais tempo no estado em que desenvolvem mais tensão. Assim, a alteração em qualquer um ou em ambos momentos da fase de desenvolvimento de tensão, do ciclo das pontes cruzadas, pode modificar a produção de força muscular (GRANGE, VANDENBOOM \& HOUSTON, 1993; MACINTOSH \& RASSIER, 2002; RASSIER \& MACINTOSH, 2000; SALE, 2002; TUBMAN, RASSIER \& MACINTOSH, 1996; VANDENBOOM \& HOUSTON, 1996).

Um outro evento local, que também pode estar relacionado com as alterações momentâneas na produção de força, é a modificação aguda da arquitetura do músculo esquelético. Segundo LIEBER e FRIDÉN (2000) a arquitetura do músculo esquelético diz respeito a maneira como as fibras musculares estão posicionadas dentro do músculo, em relação ao seu eixo de geração de força. O posicionamento das fibras musculares pode ser oblíquo ou paralelo ao eixo de geração de força. A disposição das fibras musculares em relação ao seu eixo de geração de força tem implicações funcionais. Quanto maior o ângulo de inclinação das fibras musculares, em relação ao eixo de geração de força, menos eficiente a transmissão da tensão desenvolvida ao seu respectivo tendão. Por outro lado, a produção de tensão pode ser maior em razão da maior acomodação de sarcômeros em paralelo, que ocorre quando as fibras se dispõem obliquamente em relação ao eixo de geração de força do músculo.

Recentemente, MAHLFELD, FRANKE e AWISZUS (2004) verificaram que o ângulo de inclinação das fibras musculares diminui nos instantes subseqüentes a realização de contrações voluntárias máximas. Uma vez que ângulos de inserção menores favorecem a transmissão da força produzida para os tendões, pode-se esperar que esta modificação aguda na arquitetura muscular implique em alterações no desempenho da força após a ativação prévia. Contudo, MAHLFELD, FRANKE e AWISZUS (2004) não investigaram o efeito desta alteração no desempenho. Além disso, a diminuição no ângulo de inclinação observada neste 
estudo foi de apenas dois graus, o que produziria um ganho absoluto de força muito pequeno, segundo os autores

Um outro fato importante a ser considerado, quando se pretende desencadear o efeito de potencialização, é a característica do músculo que se está estimulando. A potencialização parece ser mais pronunciada em músculos com predominância de fibras tipo II, em comparação aqueles em que predominam as fibras tipo 1. Por exemplo, no estudo de HAMADA, SALE e MACDOUGALL (2000), a estimulação dos extensores do joelho, com 1CVM de 10s, resultou em maior potencialização naqueles sujeitos com maior porcentagem de fibras tipo II. Utilizando um protocolo de estimulação diferente, composto por 16 CVIM de 5s, HAMADA, SALE, MACDOUGALL e TARNOPOLSKY (2003) demonstraram, novamente, que indivíduos com predominância de fibras tipo II, no músculo vasto lateral, são mais suscetíveis a potencialização.

LOUGHEED e HICKS (1999) estudaram os efeitos de diferentes tipos de contrações (isométricas, concêntricas e excêntricas) nos músculos flexores plantar e dorsi-flexores do tornozelo. Neste estudo, a potencialização foi evidente nos flexores plantar, os quais são músculos com predominância de fibras tipo II, mas não se manifestou nos dorsi-flexores, onde predominam fibras tipo I. Os resultados foram semelhantes para os três tipos de contrações utilizadas. A maior potencialização em fibras tipo Il é explicada pelo fato desse tipo de fibra ser mais suscetível a fosforilação da miosina RCL (GRANGE, VANDENBOOM \& HOUSTON, 1993; MOORE \& STULL, 1984). Uma explicação para essa diferença entre fibras rápidas e lentas deve-se a atividade das enzimas quinase e fosfatase da miosina RCL nesses tipos de fibras. Em ratos, a atividade da quinase é três vezes maior nas fibras tipo Il do que nas fibras tipo I, o que explicaria sua maior capacidade de fosforilação. Além disso, a taxa de defosforilação é muito maior nas fibras lentas, uma vez que nessas fibras a atividade da fosfatase é maior do que nas fibras rápidas (HOUSTON, GREEN \& STULL, 1985)

Não se pode deixar de citar, no entanto, que outros estudos demonstraram ocorrência de potencialização em fibras tipo I ou deram evidências de sua ocorrência. BELANGER e MCCOMAS (1989), em um estudo que teve como objetivo analisar possiveis mudanças da potencialização em decorrência da puberdade, verificaram a ocorrência de potencialização tanto nos músculos flexores plantar do tornozelo como nos dorsi-flexores, demonstrando que músculos com predominância de fibra tipo I também são suscetíveis a potencialização. 
HAMADA, SALE e MACDOUGALL (2000) demonstraram ocorrência de potencialização em um estudo que envolveu triatletas, corredores de longa distância, praticantes de treinamento de força em nivel recreativo e sujeitos sedentários. Neste estudo, os diferentes grupos de sujeitos foram estimulados nos músculos tríceps sural e tríceps braquial com uma única contração voluntária isométrica máxima de 10 segundos de duração (1CVIM de 10s). A manifestação da PPA se deu apenas naqueles músculos que eram envolvidos em algum tipo de treinamento. Por exemplo, triatletas e praticantes de treinamento com peso, que treinam tanto membros superiores quanto inferiores, tiveram potencializado os extensores do cotovelo e os flexores plantar. Por outro lado, corredores de longa distância, que somente treinam membros inferiores, manifestaram a PPA apenas nos flexores plantar.

Segundo os autores, considerando-se que atletas de corridas de longa distância possuem predominantemente fibras musculares de tipo I, o resultado mais esperado seria uma depressão da potencialização ao invés de seu aumento. No entanto, eles apontam que o treinamento de resistência aeróbia pode aumentar a potencialização, uma vez que, as adaptações ocorridas em função do treinamento dessa capacidade motora, como o aumento do conteúdo de miosina de cadeia leve "rápida" em fibras do tipo I, podem ampliar a capacidade de fosforilação da miosina RCL, que por sua vez é o provável mecanismo da PPA. Estes resultados sugerem que a manifestação da potencialização parece ser influenciada por fatores genéticos mas também pelas adaptações promovidas pelo treinamento

A potencialização da força também pode ser explicada por alterações no padrão de ativação neural. GÜLLICH e SCHMIDTBLEICHER (1996) verificaram que a amplitude do reflexo de Hoffmann (reflexo $\mathrm{H}$ ), avaliado após a realização de 1 CVIM de $5 \mathrm{~s}$, foi maior que a amplitude obtida antes, nos músculos gastrocnêmios e sóleo, de sujeitos atletas e não atletas. $\mathrm{O}$ reflexo $\mathrm{H}$ é um reflexo artificial, utilizado na avaliação da excitabilidade da via reflexa, que consiste em aplicar um choque elétrico em um nervo periférico (ENOKA, 1988). A resposta do sistema neuromuscular ao reflexo $\mathrm{H}$ é obtida através da eletromiografia do músculo estimulado. Quanto maior a amplitude das ondas $\mathrm{H}$, obtidas na eletromiografia, maior o número de unidades motoras que contribuíram para essa resposta, em função de um maior nível de excitabilidade do pool de motoneurônios (ENOKA, 1988).

GÜLLICH e SCHMIDTBLEICHER (1996) verificaram que o aumento da amplitude do reflexo H correlacionava-se $(r=0,89)$ com o aumento do desempenho da força explosiva, no movimento de flexão plantar, também avaliado após 1CVIM de 5s. De acordo com os autores, 
o aumento do desempenho da força explosiva foi conseqüencia da maior excitabilidade dos motoneurònios.

Já BAKER (2003) menciona uma série de mecanismos neurais que poderiam, isolada ou conjuntamente, serem responsáveis pela potencialização. Segundo o autor, a potencialização pode ser explicada por eventos como, aumento do recrutamento de unidades motoras, melhora na sincronia dos disparos dos impulsos nervosos, diminuição da influência de mecanismos inibitórios centrais (célula de Renshaw) e periféricos (órgão tendinoso de Golgi), e aumento da inibição recíproca da musculatura antagonista.

\subsection{Características das atividades estimuladoras da potencialização}

A potencialização da força tem sido estudada em fibras musculares isoladas e em músculos inteiros, de animais ou humanos, através de ativações involuntárias ou voluntárias. Quando a potencialização é induzida por ativação involuntária o efeito desencadeado é referido por potencialização pós-tetania (PPT). Quando a indução é voluntária, o efeito obtido é referido por potencialização pós-ativação (PPA) (VANDERVOORT, QUINLAN \& MCCOMAS, 1983). A indução da potencialização com estimulação involuntária, conduzida em ambiente de laboratório, consiste em aplicar na amostra estudada uma corrente elétrica de alta freqüência, com duração entre cinco e dez segundos. Segundo alguns autores, esta estimulação deve ser de alta freqüência, a fim de que seja produzida uma contração tetânica. A estimulação involuntária pode ser aplicada sobre o nervo motor ou diretamente no músculo (GRANGE, VANDENBOOM, XENI \& HOUSTON, 1998; MACINTOSH \& WILLIS, 2000; VERGARA, RAPOPORT \& NASSAR-GENTINA, 1977).

Baseando-se no fato de que, quando a indução é involuntária, a obtenção de uma contração tetânica é necessário para induzir a potencialização, foi sugerido que a indução voluntária deveria ser realizada através de contrações musculares de alta intensidade. Para isso, os exercícios deveriam ser realizados utilizando carga máxima ou próxima da máxima (GOSSEN \& SALE, 2000; GÜLLICH \& SCHMIDTBLEICHER, 1996; PÄÄSUKE, ERELINE \& GAPEYEVA, 2000; SKURVYDAS \& ZACHOVAJEVAS, 1998; VANDERVOORT, QUINLAN \& MCCOMAS, 1983). Alguns estudos utilizaram exercícios com essas características e tiveram êxito em induzir a potencialização. Em muitos casos os exercícios eram estáticos, ou seja, composto por contrações isométricas máximas de duração 
entre très e 10 segundos (FRENCH, KRAEMER \& COOKE, 2003; GÜLLICH \& SCHMIDTLEICHER, 1996; HAMADA, SALE \& MACDOUGALL, 2000; VANDERVOORT, QUINLAN \& MCCOMAS, 1983). Exercicios de força dinâmica, com cargas que permitam a realização de uma a cinco repetições máximas (1-5RM) também têm sido utilizados com bastante freqüência (CHIU, FRY, WEISS, SCHILLING, BROWN \& SMITH, 2003; EVANS, DURHAM, HODGKINS, SINCLAIR \& ADAMS, 2001; GOURGOULIS et al., 2003; YOUNG, JENNER \& GRIFFTHS, 1998). No entanto, recentemente, BAKER (2003) mostrou que a potencialização do desempenho, em membros superiores, pode ser induzida com exercícios de intensidade mais baixa, isto é, $65 \%$ de $1 \mathrm{RM}$, colocando em dúvida a necessidade de ativar os músculos com alta intensidade para produzir a potencialização.

Um outro aspecto importante, que se deve atentar, relaciona-se a duração dos intervalos de descanso entre as séries de exercícios usados para induzir a PPA. GÜLLICH e SCHMIDTBLEICHER (1996) verificaram que a duração dos intervalos entre os estímulos pode influenciar a magnitude da potencialização atingida. Neste estudo, foram comparados protocolos com intervalos de diferentes durações. Os resultados mostraram que maiores níveis de potencialização foram conseguidos com baixa densidade de estímulos. Ou seja, quando os intervalos entre os estímulos duravam cinco minutos, a potencialização atingida era maior, comparada à obtida quando os intervalos duravam um ou três minutos.

Também é importante observar o intervalo entre a atividade estimulante e o exercício através do qual a potencialização será avaliada. RASSIER e MACINTOSH (2000) afirmaram que durante a estimulação, dois processos acontecem simultaneamente no músculo: um que diminui o desempenho da força ativa (fadiga) e outro que o aprimora (potencialização). Segundo estes autores, o resultado da interação entre fadiga e potencialização pode implicar na diminuição da força ativa (força produzida pela interação entre actina e miosina), no seu aumento, ou em nenhuma alteração da mesma. A ocorrência de um ou de outro comportamento depende do momento em que o desempenho for avaliado. Quando a avaliação se dá imediatamente após a estimulação, os efeitos da fadiga mascaram os da potencialização o que pode implicar na diminuição da força ativa ou na manutenção da mesma. Quando é permitido um intervalo de três a cinco minutos entre o estímulo e o desempenho, os efeitos da fadiga se dissipam, enquanto os da potencialização, embora diminuídos, ainda se manifestam. Nesta situação, o desempenho da força apresenta-se aprimorado. 
Fator importante da potencialização, que também justifica o interesse em seu estudo e aplicação prática ao esporte, refere-se ao seu tempo de manifestação. Alguns estudos demonstraram que o aumento temporário do desempenho muscular pode ser percebido até 20 minutos após a realização de uma atividade estimuladora (GÜLLICH \& SCHMIDTBLEICHER, 1996; O'LEARY, HOPE, \& SALE, 1997; TRIMBLE \& HARP, 1998; VANDERVOORT, QUINLAN \& MCCOMAS, 1983; VERGARA, RAPOPORT \& NASSAR-GENTINA, 1977). Interessantemente, o início da manifestação do fenômeno acontece em diferentes instantes quando avaliada através de ativação involuntária ou voluntária. Quando avaliada involuntariamente, a potencialização é notada já nos primeiros segundos após a atividade estimuladora. No entanto, quando avaliada através do desempenho em uma tarefa motora sua manifestação somente se verifica três ou quatro minutos mais tarde. Segundo RASSIER e MACINTOSH (2000) esse retardo na manifestação da potencialização quando avaliada por intermédio de contrações voluntárias poderia estar relacionado com a interação entre os mecanismos causadores de fadiga e potencialização.

\subsection{Avaliação da manifestação da potencialização}

Da mesma maneira que a estimulação da potencialização, a sua manifestação também é avaliada através de ativações musculares involuntárias ou voluntárias. Nos estudos nos quais a avaliação do efeito de potencialização é feita através de contrações involuntárias, costuma-se comparar o desempenho muscular gerado antes com o gerado após a atividade estimuladora, através da resposta a um estimulo elétrico isolado, conhecida como "twitch". O desempenho muscular, em resposta a estimulação, pode ser avaliado através da combinação de informações provenientes do registro eletromiográfico (EMG) e de um dinamômetro. Utiliza-se para comparação dados como grau de ativação muscular, velocidade, taxa de desenvolvimento de força, pico de força, tempo para alcance do pico de força, tempo de duração da contração muscular e tempo de meio relaxamento (EBBEN, JENSEN \& BLACKARD, 2000; O'LEARY, HOPE \& SALE, 1997).

Alguns estudos avaliaram o efeito de potencialização através de contrações musculares voluntárias utilizando movimentos uniarticulares, como por exemplo a extensão de joelhos (HAMADA, SALE, MACDOUGALL \& TARNOPOLSKY, 2003; HUGHES, GOSSEN \& SALE, 2001) e a flexão plantar (HAMADA, SALE \& MACDOUGALL, 2000; PÄÄSUKE, 
ERELINE \& GAPEYEVA, 2000). No entanto, o interesse em aplicar a PPA ao esporte inspirou uma serie de estudos nos quais a potencialização foi avaliada através de tarefas motoras complexas. Os exercicios mais freqüentemente utilizados para esse propósito são os saltos horizontais e verticais com ou sem contramovimento (CHIU et al., 2003; KOCH et al., 2003; RADCLIFFE \& RADCLIFFE, 1996) e o arremesso de barra no exercício supino (BAKER, 2003; HRYSOMALLIS \& KIDGELL, 2001). O interesse especial em verificar a potencialização nesses exercícios se justifica pelo fato de serem utilizados em um grande número de modalidades esportivas.

\subsection{Aplicação prática do fenômeno de potencialização}

Alguns estudos demonstraram que exercicios dependentes da manifestação da força explosiva, como saltos (vertical e horizontal), chutes e arremessos, podem ser potencializados, ou seja, apresentar melhora aguda do desempenho quando, no aquecimento, são realizados exercicios de força (GOURGOULIS et al., 2003; GÜLLICH \& SCHMIDTBLEICHER, 1996).

Por exemplo, o desempenho do salto vertical pode sofrer uma melhora temporária, de $3,3 \%$, após os sujeitos realizarem três contrações voluntárias isométricas máximas, de cinco segundos de duração (3CVIM de 5s), utilizando o exercício leg press (GÜLLICH \& SCHMIDTBLEICHER, 1996). Verificou-se, também, um aumento na distância do salto horizontal, de $1,5 \%$, após os indivíduos realizarem quatro séries, com carga de $75-85 \%$ de 4RM, no exercício arranque (RADCLIFFE \& RADCLIFFE, 1996). O arremesso da barra no exercício supino (realizado no aparelho Smith) foi $3 \%$ mais potente, 5 minutos após a realização de uma série de cinco repetições máximas ( 1 x 5RM), no mesmo exercício (EVANS et al., 2001).

Entretanto, apesar dos estudos citados suportarem ser vantajoso para o desempenho incluir exercícios de força no aquecimento, outros estudos colocam em dúvida a validade desse procedimento, uma vez que seus resultados não apontaram qualquer beneficio de tal prática. Por exemplo, a realização de 1 x 5RM, no agachamento, não provocou qualquer alteração na altura do salto vertical com contramovimento, avaliado quatro minutos após o exercício de força (JENSEN \& EBBEN, 2003). O desempenho do salto vertical também não foi melhorado quando precedido por $3 \mathrm{CVIM}$ de $5 \mathrm{~s}$, usando o exercício leg press (BATISTA, COUTINHO, BARROSO \& TRICOLI, 2003). Além disso, a produção de potência em 
membros superiores, não foi melhorada após a realização 1 × 3-5RM no exercício supino (EBBEN et al., 2000; HYRSOMALLIS \& KIDGELL, 2001).

Parece que a potencialização da força explosiva, provocada pela realização prévia de exercícios de força, é um fenômeno condicionado a alguns fatores como características do exercicio estimulador, nível de força máxima e estado de treinamento do indivíduo. Segundo GÜLLICH e SCHMIDTBLEICHER (1996), a potencialização depende das características dos exercícios de força utilizados no aquecimento. Em seu estudo verificou-se que as alterações no desempenho estão condicionadas ao volume, intensidade e densidade dos exercícios de força. Por exemplo, o aumento do desempenho do salto vertical foi maior quando o exercício precedente compunha-se de 3CVIM de 5s, em comparação ao aumento induzido por 1 ou 2CVIM. Além disso, os incrementos na altura do salto vertical foram obtidos quando o exercício de força foi realizado com carga de 1RM ou 5\% superior a ela (contrações excêntricas). Por outro lado, quando o exercício foi realizado com carga de $90 \%$ de 1RM não houve qualquer melhora na altura do salto. Os aumentos no desempenho também foram mais expressivos quando, entre as séries, respeitou-se intervalos de três ou cinco minutos.

Outros estudos sugerem que a eficiência dos exercícios de força, em induzir potencialização, depende do nivel de força dos sujeitos. Em dois estudos, demonstrou-se que a melhora momentânea do desempenho era maior nos indivíduos com maior nível de força dinâmica máxima, avaliada no teste uma repetição máxima (1RM). Por exemplo, no estudo de DUTHIE, YOUNG e AITKEN (2002), a potencialização do pico de força, gerado durante o salto vertical com carga adicional ( $30 \%$ 1RM), foi superior nos sujeitos com melhor desempenho no teste de força dinâmica máxima (FDM) de 3RM, após realizarem $1 \times 3 \mathrm{RM}$ no agachamento. No estudo de GOURGOULIS et al. (2003) a altura do salto vertical com contramovimento também foi superior nos sujeitos com maior nível de FDM (1RM), após realizarem duas repetições, com as cargas de 20,40,60, 80 e 90\% de 1RM, no agachamento. Contudo, DUTHIE, YOUNG e AITKEN (2002) não verificaram qualquer alteração na altura do salto vertical com carga adicional, quando analisados os sujeitos com melhor desempenho no teste de 3RM. Da mesma forma, SCOTT e DOCHERTY (2004) não verificaram melhoras na altura e distância dos saltos vertical e horizontal, respectivamente, de sujeitos com experiência em treinamento de força, após realizarem 1 x $5 R M$ no agachamento. HYRSOMALLIS e KIDGEL (2001) testaram a potencialização em indivíduos não atletas, porém, experientes em treinamento de força, e não verificaram qualquer alteração na força 
explosiva de membros superiores após a realização de 1 × 5RM no exercício supino. Além disso, SLEIVERT, CAMPBELL e SALE (1999) submeteram, por um periodo de 10 semanas, um grupo de individuos a um programa de treinamento de força isométrica máxima, e não verificaram qualquer potencialização do desempenho da extensão de joelhos, antes ou após o periodo de treinamento. Ou seja, apesar do programa de treinamento haver elevado o nivel de força dos sujeitos, eles continuavam incapazes de produzir o efeito de potencialização.

Também foi sugerido que o efeito de potencialização é mais pronunciado em atletas envolvidos em modalidades esportivas de potência mas, os estudos a esse respeito, também, apresentam resultados contraditórios. CHIU et al. (2003) compararam o efeito de potencialização, entre atletas de diferentes modalidades e indivíduos classificados como fisicamente ativos, em resposta ao aquecimento com cinco séries de uma repetição com carga de $90 \%$ de 1RM. O desempenho do salto vertical foi potencializado nos atletas, mas não sofreu qualquer alteração nos fisicamente ativos.

No estudo de FRENCH, KRAEMER e COOKE (2003) indivíduos atletas, de modalidades de potência, tiveram potencializada a altura de seu salto vertical após a realização de 3 x 3CVIM de $3 \mathrm{~s}$. Contudo, nesse estudo não houve comparação do desempenho dos atletas com um grupo de indivíduos não atletas.

$\mathrm{KOCH}$ et al. (2003) compararam o efeito de potencialização, no salto horizontal, entre atletas (velocistas e saltadores) universitários e sujeitos não treinados. Eles não verificaram qualquer diferença entre seus desempenhos, 15 minutos após realizarem $1 \times 3 R M$ no agachamento, com cargas de 50, 75 e $85 \%$ de 1RM. EBBEN et al. (2000) testaram a potencialização em atletas de modalidades de potência, e também não observaram qualquer alteração no desempenho da força explosiva de membros superiores, após a realização de $1 \times$ 5RM no exercício supino.

GÜLLICH e SCHMIDTBLEICHER (1996) mostraram que a potencialização foi superior quando induzida em indivíduos atletas de força explosiva em comparação a indivíduos fisicamente ativos. Contudo, isso foi verificado no desempenho de uma contração muscular involuntária. Não se pode afirmar que o mesmo comportamento seria verificado em tarefas motoras voluntárias como, por exemplo, o salto vertical.

RADCLIFFE e RADCLIFFE (1996) submeteram atletas de nível universitário, a um aquecimento que consistiu de quatro séries de 4RM com $75-85 \%$ de $1 \mathrm{RM}$ no agachamento e no arranque. A distância do salto horizontal, avaliado três minutos após, não foi potencializada 
quando utilizado o exercício agachamento, porem, foi $1 \%$ mais distante quando utilizado o exercicio arranque.

Como se vê, ainda não é claro se o estado de treinamento do sujeitos influencia a manifestação da potencialização. É possivel que a intensidade dos exercicios de força não tenha sido suficiente para estimular a potencialização, já que, em todos estudos sobre o efeito do estado de treinamento, foram utilizadas contrações dinâmicas (iguais ou inferiores a 1RM). Em um único estudo comparou-se a eficiência dos dois tipos de contrações em induzir a potencialização em indivíduos atletas, somente as CVIM se mostram eficientes (GÜLLICH \& SCHMIDTBLEICHER, 1996). Além disso, como sugere o estudo de RADCLIFFE e RADCLIFFE (1996), outros fatores, como o tipo de exercício utilizado no aquecimento, podem interferir na manifestação da potencialização. Até o momento, nenhum estudo investigou a influência do estado de treinamento utilizando contrações voluntárias isométricas máximas como exercício de força para induzir a potencialização. Contudo, ainda não foi investigado se indivíduos com maior nível da força explosiva e da força máxima são mais suscetiveis a potencialização utilizando-se CVIM para induzi-la.

Além disso, os resultados desse estudo não deixaram claro se a potencialização da força explosiva depende do nível da força máxima ou do nivel da força explosiva dos sujeitos, já que não se comparou o nível dessas variáveis de desempenho entre os sujeitos envolvidos no estudo. Assim, para sugerir a inclusão de exercícios de força no aquecimento, é preciso conhecer quais sujeitos são suscetíveis ao fenômeno e quais as características do exercício capaz de induzí-lo.

\section{MATERIAIS E MÉTODOS}

\subsection{Amostra}

Inicialmente, 30 individuos do sexo masculino, foram selecionados para participar do estudo. A seleção foi feita baseando-se na experiência do sujeito em treinamento de força. Três indivíduos não terminaram o estudo. A amostra foi dividida em três grupos, de acordo com o tipo de experiência do sujeito em treinamento de força. Um grupo foi formado por atletas, especialistas em provas de potência, de nível internacional ( $A T L=10)$. Um segundo grupo foi formado por indivíduos experientes em treinamento de força (TRF=7) com o 
propósito de aumentar a massa muscular. Um terceiro grupo foi composto por individuos fisicamente ativos ( $F I S=10)$. Os indivíduos selecionados para compor o grupo ATL relataram experiência média de três anos em treinamento de força, orientado ao aprimoramento da força explosiva dos membros inferiores. Os sujeitos destinados ao grupo TRF relataram experiência média de um ano de treinamento de força, visando hipertrofia ou ganhos de força muscular nos membros inferiores. Os sujeitos do grupo FIS, por sua vez, não estavam envolvidos em qualquer tipo de treinamento de força, havia pelo menos seis meses. Estes sujeitos, no entanto, realizavam atividade física, com o propósito de melhorar seu condicionamento, em pelo menos dois dias da semana.

Foram considerados inaptos a participar do estudo, os sujeitos que relataram lesões neuromusculares ou articulares, no periodo de seis meses anteriores ao estudo. As informações necessárias para satisfazer os critérios de seleção, foram obtidas através de um questionário (ANEXO I). Os sujeitos foram orientados a abster-se de atividades extenuantes ou não usuais, nas 24 horas que antecediam aos testes. Foi solicitado aos sujeitos que assinassem um termo - de consentimento informado para participar do estudo (ANEXO II). Com o propósito de caracterizar a amostra, foram coletados dados dos sujeitos referentes à idade, estatura, massa corporal, e força dinâmica máxima, através do teste para uma repetição máxima (1RM) no exercício leg press. As características dos sujeitos encontram-se resumidas na TABELA 1.

\subsection{Familiarização}

Uma semana antes do início dos experimentos foi realizada uma sessão de familiarização. Esta sessão teve os seguintes propósitos:

- Esclarecer os sujeitos a respeito dos objetivos do estudo, dos procedimentos à que seriam submetidos e assinatura do termo de consentimento informado (ANEXO II);

- Coletar dados referentes à idade, estatura, massa corporal dos sujeitos;

- Orientar e familiarizar os sujeitos em relação à técnica correta de execução salto vertical com contramovimento e a todos os procedimentos experimentais;

- Determinar o posicionamento dos sujeitos, no aparelho leg press, para o teste de força dinâmica máxima (1RM) e para as CVIM que, posteriormente, seriam utilizadas nos protocolos de aquecimento;

- Avaliar a força dinâmica máxima (teste de 1RM). 
Organização dos procedimentos da familiarização

Após a assinatura do consentimento informado e das avaliações de massa corporal e estatura, os sujeitos recebiam orientações a respeito da técnica de execução do salto vertical com contramovimento e, na seqüência, eram solicitados a executar uma série de saltos (três a cinco saltos) para consolidarem o aprendizado da técnica.

Em seguida, eram feitas as aferições das angulações dos joelhos e quadril que seriam utilizadas no teste de $1 \mathrm{RM}\left(80-85^{\circ}\right.$ e $55-65^{\circ}$, respectivamente) e durante as CVIM $\left(80-90^{\circ}\right.$ e 55-65 , respectivamente). Para isso, foi utilizado o goniômetro manual RAJOVALT n. ${ }^{\circ} 337$. A angulação do quadril foi aferida através das linhas que ligam os pontos anatômicos referentes à linha axilar média, trocanter maior do fềmur e côndilo lateral do fềmur. Por sua vez, a angulação do joelho foi aferida pelas linhas que ligam os pontos anatômicos referentes ao trocanter maior do fềmur, côndilo lateral do fềmur e maléolo lateral. Além disso, avaliou-se a força dinâmica máxima de membros inferiores dos sujeitos, através do teste de uma repetição máxima (1RM) no exercício leg press. A realização desse teste seguiu as orientações da "American Society of Exercise Physiologists" (ASEP), para testes de 1RM (BROWN \& WEIR, 2001). Ou seja, os sujeitos foram submetidos a um aquecimento geral por cinco minutos, na esteira ergométrica em velocidade de $8-8,5 \mathrm{Km} / \mathrm{h}$, seguido pelo alongamento da musculatura que seria envolvida no teste. Depois disso, realizavam duas séries de aquecimento específico no leg press. A carga inicial para o teste de $1 \mathrm{RM}$ era estimada em três vezes a massa corporal do indivíduo. Na primeira série eram feitas cinco repetições, com $50 \%$ da carga estimada para 1RM. Na segunda, três repetições, com $70 \%$ da carga estimada para 1RM. Entre as séries de aquecimento era respeitado um intervalo de dois minutos. Entre a segunda série e o início do teste os sujeitos descansavam três minutos.

Os incrementos de carga durante o teste eram progressivos, porém, sua magnitude era determinada de acordo com a percepção do avaliador. A determinação da carga máxima para IRM era feita em cinco tentativas. Para que a tentativa fosse considerada válida, os sujeitos precisavam executar um ciclo completo de movimento. Os sujeitos iniciavam e terminavam o ciclo de movimento com os joelhos em extensão completa. No ponto intermediário do ciclo de movimento os joelhos e o quadril deviam atingir entre $80-85^{\circ}$ e $55-65^{\circ}$ graus de flexão, respectivamente, antes de iniciar a fase de extensão e voltar a posição inicial/final. Antes da realização do teste era marcado na plataforma de apoio, do aparelho leg press, o local exato 
onde os sujeitos deveriam posicionar seus pés no momento da execução. Também se delimitava um ponto para a amplitude de deslocamento da plataforma. Com esses dois registros era possivel controlar as angulações de joelhos e quadril, previamente determinadas, de forma bastante prática e precisa.

Todos as sessões de teste de IRM foram acompanhadas por três ou quatro avaliadores treinados para esta finalidade. Além disso, foram instaladas correntes que serviam como dispositivo de segurança, caso o sujeito não suportasse a carga seleciona. Estas medidas foram adotadas a fim de evitar que a insegurança do sujeito, em realizar o teste, fosse um fator limitador de seu desempenho.

\subsection{Desenho experimental e procedimentos do estudo}

As sessões experimentais foram sempre precedidas pela atividade de aquecimento que consistiu de cinco minutos de corrida, em esteira ergométrica, a $8-8,5 \mathrm{~km} / \mathrm{h}$, seguida de exercicios de alongamento e duas contrações isométricas submáximas no leg press (BISHOP, 2003a, 2003b). Entre as contrações isométricas os sujeitos descansavam por um minuto. Em seguida ao aquecimento os sujeitos realizavam um dos seguintes tratamentos:

\section{Tratamento 1}

Avaliação do salto vertical pré-tratamento $\rightarrow$ 1CVIM $5 \mathrm{~s}$ (tratamento) $\rightarrow$ reavaliação do salto vertical ao $4^{\circ}$ e $8^{\circ}$ minutos após o tratamento.

\section{Tratamento 2}

Avaliação do salto vertical pré-tratamento $\rightarrow$ ICVIM 5s (tratamento) $\rightarrow$ reavaliação do salto vertical ao $8^{\circ}$ minuto após o tratamento.

\section{Tratamento 3}

Avaliação do salto vertical pré-tratamento $\rightarrow$ 3CVIM 5s (tratamento) $\rightarrow$ reavaliação do salto vertical ao $4^{\circ}$ e $8^{\circ}$ minutos após o tratamento. 
Tratamento 4

Avaliação do salto vertical pré-tratamento $\rightarrow 3$ CVIM $5 \mathrm{~s}$ (tratamento) $\rightarrow$ reavaliação do salto vertical ao $8^{\circ}$ minuto após o tratamento.

Tratamento 5 (controle)

Avaliação do salto vertical $\rightarrow$ intervalo de 4 minutos $\rightarrow$ reavaliação do salto vertical.

Foi observado um intervalo de aproximadamente dois minutos entre o término do aquecimento e a avaliação do salto vertical pré-tratamento. O mesmo intervalo foi respeitado entre a avaliação do salto vertical e o tratamento (CVIM). Estes intervalos foram determinados para que os indivíduos não perdessem os beneficios proporcionados pelos exercícios de aquecimento e para que se deslocassem entre laboratórios, a fim de se preparar para o próximo procedimento. Os tratamentos foram realizados em sessões independentes, separadas por um intervalo médio de 48 horas. A realização das sessões foi determinada através de ordem aleatória contra-balanceada. Para isso utilizou-se o modelo dos quadrados latinos adaptado por Williams (KUEHL, 2000).

\subsection{Tratamento experimental}

As cinco visitas após a familiarização foram destinadas à aplicação dos procedimentos experimentais. Todos os sujeitos envolvidos no estudo foram submetidos a dois diferentes tratamentos e também a condição controle, os quais aconteceram em diferentes sessões. Um dos tratamentos era composto por uma contração voluntária isométrica máxima de cinco segundos de duração (1CVIM 5s), enquanto que o outro era composto por três contrações voluntárias isométricas máximas de cinco segundos de duração (3CVIM 5s). Foi respeitado um intervalo de cinco minutos entre cada contração quando o tratamento era composto por 3CVIM 5s (GÜLLICH \& SCHMIDTBLEICHER, 1996). Na situação controle os sujeitos descansaram, passivamente, por quatro minutos entre duas séries de cinco saltos. Cada tratamento (1CVIM 5s e 3CVIM 5s) foi aplicado em duas sessões, pois, em cada uma delas a reavaliação pós-tratamento acontecia em diferentes intervalos de tempo.

As CVIM foram realizadas no aparelho leg press de marca NAKAGYM modelo NK 5070. A plataforma de apoio dos pés foi estabilizada com uma corrente a fim de impedir seu 
deslocamento no momento da aplicação de força (ANEXO III). A estabilização da plataforma foi feita de maneira que, ao se posicionarem para realizar o exercício, os sujeitos mantinham as articulações dos joelhos e do quadril entre $80-90^{\circ}$ e $55-65^{\circ}$, respectivamente.

\subsection{Avaliações dos saltos verticais}

Procedimentos

Antes de serem submetidos aos tratamentos (1CVIM 5s ou 3CVIM 5s) cada sujeito realizava uma série de cinco saltos verticais com contramovimento (SVCM). As avaliações do SVCM após os tratamentos, também, incluiam séries de cinco saltos. No entanto, em duas sessões foram efetuadas duas séries (cinco saltos em cada série), uma ao $4^{\circ}$ e outra ao $8^{\circ}$ minuto, após o tratamento (1CVIM 5s e 3CVIM 5s). Em outras duas sessões, o SVCM foi avaliado apenas ao $8^{\circ}$ minuto após o tratamento. Os desempenhos dos SVCM realizados ao $8^{\circ}$ minuto, em cada uma das sessões, foram comparados entre si para verificar uma possível influência dos saltos realizados ao $4^{\circ}$ minuto. Entre os saltos da série respeitava-se um intervalo de 15 segundos (READ, 1998).

Durante a realização dos SVCM os sujeitos mantinham suas mãos apoiadas na cintura. Antes e durante as avaliações dos saltos os sujeitos eram orientados a saltar o mais alto possível. A análise dos dados foi feita considerando o desempenho médio de três saltos, após a eliminação dos saltos de melhor e pior desempenho. Este procedimento foi adotado a fim de diminuir a influência da variabilidade dos saltos nos cálculos estatísticos. Também foi feita análise somente pelo salto de melhor desempenho.

Instrumento usado para avaliar o salto vertical com contramovimento

O SVCM foi avaliado utilizando uma plataforma de força da marca AMTI $^{\circledR}$ modelo OR6-WP. Foram analisados os dados referentes ao componente vertical da força de reação do solo $(\mathrm{Fz})$, coletados com a freqüência de $1000 \mathrm{~Hz}$. A filtragem on-line do sinal foi feita com um filtro Butterworth, do tipo passa baixa, com freqüência de corte de $200 \mathrm{~Hz}$. Para eliminar efeitos de ruídos adicionais, o sinal foi novamente tratado por um filtro digital Butterworth de quarta ordem e passa baixa, com freqüência de corte a $30 \mathrm{~Hz}$. Os cálculos das varáveis altura 
do salto, taxa de desenvolvimento de força média e pico de força, foram feitas através de um programa desenhado no Visual Basic ${ }^{\circledR}$.

Cálculo da altura do salto

A altura do salto foi calculada através do método do impulso. Esse método baseia-se na relação Impulso-Momento. O cálculo do impulso (I) gerado na fase concêntrica do salto foi feito através da integração da área correspondente sob a curva força-tempo. Uma vez conhecido o impulso (I), pudemos calcular a velocidade do centro de massa do sujeito, no momento da decolagem (Vd) para o salto, através da fórmula:

$\mathbf{I}=\mathbf{m}(\mathbf{V} \mathbf{f}-\mathbf{V i})$

onde,

$\mathrm{Vf}=$ velocidade final $(=\mathrm{Vd})$

$\mathrm{m}=$ massa do sujeito

$\mathrm{Vi}=$ velocidade inicial $(=0)$

$\mathrm{Na}$ seqüência, calculamos a altura do salto (h) através de uma equação que descreve o movimento de projéteis:

$h=V f^{2} / 2 g$

onde,

$\mathrm{g}=$ aceleração da gravidade $\left(9,81 \mathrm{~m} / \mathrm{s}^{2}\right)$

Cálculo da taxa média de desenvolvimento de força (TDFm)

Convencionalmente, a determinação da TDFm é feita calculando a inclinação da curva força-tempo, compreendida pelo trecho, entre o início do impulso concêntrico até o pico de força (maior registro de Fz resultante). No entanto, não pudemos calcular a TDFm desta maneira, pois, em grande parte dos saltos analisados, o pico de força ocorreu muito próximo ou logo durante o impulso excêntrico, não fornecendo um intervalo adequado para o cálculo convencional. Assim, TDFm foi calculada como a inclinação da curva força-tempo desde do 
menor registro de força na fase de aceleração negativa do centro de gravidade até o pico de força.

Determinação do pico de força

O pico de força gerado durante o SVCM foi identificado como o maior valor de Fz resultante registrado durante o salto.

\subsection{Análise estatística}

Os procedimentos estatísticos do estudo foram feitos utilizando-se o pacote estatístico $\mathrm{SAS}^{\circledR}$. As comparações entre os grupos no desempenho do salto vertical (altura do salto, taxa de desenvolvimento de força e pico de força) pré e pós-tratamento experimental foram feitas utilizando modelos mistos para medidas repetidas, tendo tratamento e tempo como fatores fixos e sujeitos como fator randômico. A comparação, entre grupos, das variáveis idade, massa corporal, estatura e força dinâmica máxima (1RM), foi feita através de ANOVA one-way. Quando encontrados valores significantes de $\mathrm{F}$ foram utilizadas comparações post-hoc, com ajustamento de Tukey-Kremer, para identificar diferenças entre medias. O nível de significância adotado foi de $\mathrm{p} \leq 0,05$.

\section{RESULTADOS}

Este estudo foi desenhado para verificar o efeito combinado dos fatores experiência em treinamento de força, tratamento e tempo, sobre as variáveis dependentes: altura máxima (AS), taxa média de desenvolvimento de força (TDF média) e pico de força (PF), do salto vertical com contramovimento. Como descrito anteriormente, na seção "materiais e métodos", os sujeitos realizaram séries de cinco saltos, antes e após os tratamentos (ICVIM, 3CVIM ou Controle). No entanto, para minimizar a influência da variabilidade natural dos saltos na estatística, optou-se por descartar os saltos de melhor e pior desempenho e proceder a análise através dos saltos remanescentes. A partir disso, os dados foram analisados de duas maneiras. 
Na primeira, através do salto de melhor desempenho dentre os três saltos remanescentes. Na segunda, através da média dos três saltos.

Inicialmente serão apresentados dados referentes às características dos três grupos. Em seguida, os resultados serão apresentados em seções, agrupadas por variável. Primeiro serão apresentados os dados referentes a variável altura do salto. Em seguida, os dados referentes a taxa média de desenvolvimento de força. E por fim, os dados referentes ao pico de força.

\subsection{Caracterização da amostra}

Na TABELA 1 são apresentados as médias e os desvios-padrão da idade, peso e estatura, dos sujeitos de cada grupo. ANOVA one-way encontrou diferença significante, entre a média de idade dos grupos 1 e $3(F=4,96 ; p=0,015)$. Não foram encontradas diferenças significantes para as variáveis, massa corporal $(F=0,40 ; p=0,67)$ e estatura $(F=0,15 ; p=0,85)$

TABELA 1- Médias e desvios-padrão da idade, peso e estatura, dos sujeitos de cada grupo.

\begin{tabular}{cccc}
\hline Grupos & Idade (anos) & Massa corporal $(\mathrm{Kg})$ & Estatura $(\mathrm{cm})$ \\
\hline ATL & $22,0 \pm 4,5$ & $82,6 \pm 14,2$ & $177,7 \pm 22,8$ \\
TRF & $24,1 \pm 2,5$ & $84,7 \pm 14,5$ & $177,0 \pm 9,5$ \\
FIS & $27,3 \pm 3,7 *$ & $79,2 \pm 10,2$ & $180,9 \pm 9,1$ \\
\hline
\end{tabular}

* Diferente do Grupo ATL $(\mathrm{p} \leq 0,05)$

6.2 Comparação da força dinâmica máxima (1RM) entre os grupos

A FIGURA 1 mostra a comparação, da força dinâmica máxima, avaliada através do teste de 1RM, no exercício leg press, entre o grupo de atletas (ATL), treinados em força (TRF) e fisicamente ativos (FIS). ANOVA one-way não encontrou diferenças significantes entre a força dinâmica máxima (1RM) dos grupos ATL $(364,5 \pm 115,1 \mathrm{Kg})$, TRF $(382,9 \pm 85,4 \mathrm{Kg})$ e FIS $(304,0 \pm 47,3 \mathrm{Kg})(\mathrm{F}=2 ; \mathrm{p}=0,157)$. 
FIGURA 1 - Comparação, entre grupos, da força dinâmica máxima através do teste de 1RM no exercício leg press.

Dados referentes à variável dependente: altura do salto (AS)

\subsection{Efeito combinado dos fatores na AS.}

Nas FIGURAS 2 e 3 são apresentados os efeitos dos diferentes tratamentos (Controle, ICVIM e 3CVIM) na AS, para os diferentes grupos, analisando o salto de melhor desempenho (FIGURA 2) ou a média de três saltos (FIGURA 3). Não foram encontradas diferenças significantes na AS antes e após ( 4 ou 8 minutos após) os tratamentos (1CVIM ou 3CVIM), para nenhum dos grupos testados $(p>0,05)$. 


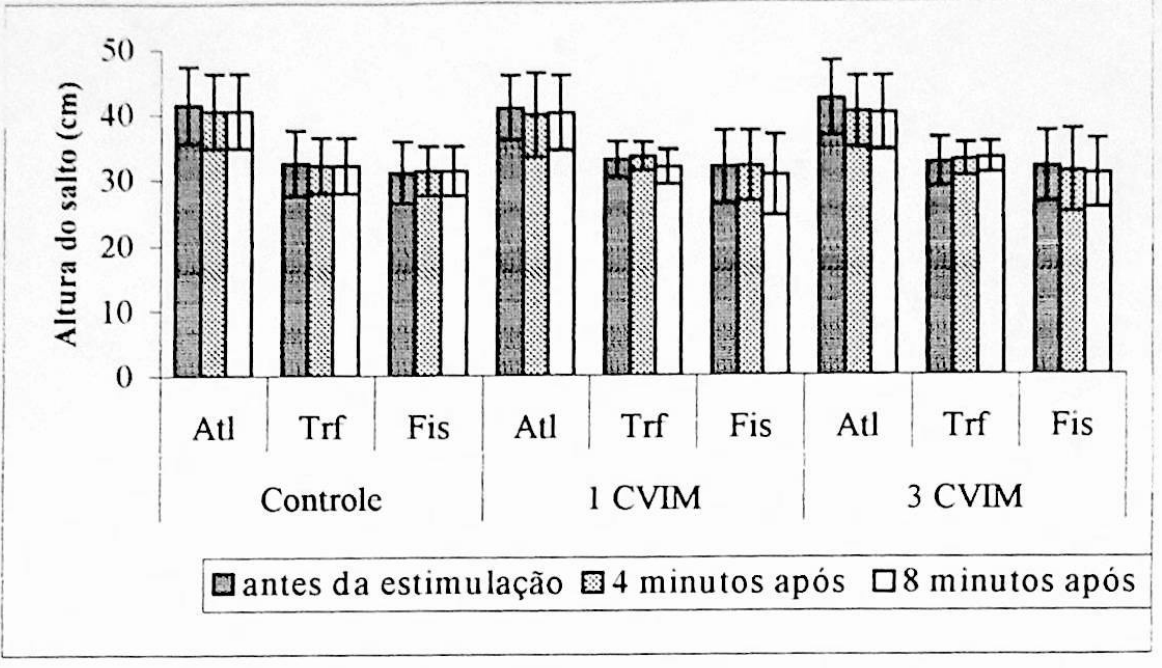

FIGURA 2 - Efeito combinado dos fatores, na AS, analisando o salto de melhor desempenho.

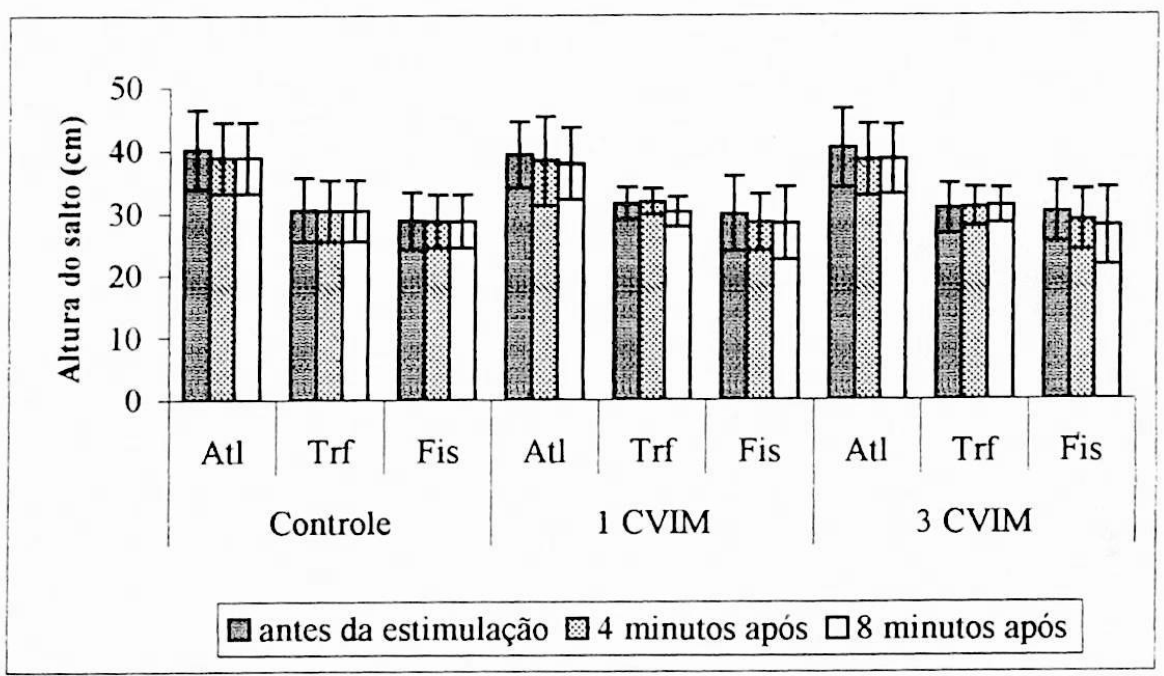

FIGURA 3 - Efeito combinado dos fatores, na AS, analisando a média de três saltos.

\subsection{Efeito principal do fator grupo na AS.}

A FIGURA 4 mostra o efeito principal do fator grupo, na altura do salto vertical com contramovimento, quando analisados o salto de melhor desempenho $(p=0,0004)$ e a média de três saltos $(p=0,0001)$. O grupo ATL saltou $8,2 \mathrm{~cm}$ mais alto que o grupo TRF $(p=0,0027)$, quando analisada a média de três saltos, e $8,1 \mathrm{~cm}(\mathrm{p}=0,0013)$, quando analisado o salto de melhor desempenho. O grupo ATL também teve melhor desempenho que o grupo FIS. Quando analisada a média de três saltos, a diferença entre estes grupos foi de $8,7 \mathrm{~cm}$ 
$(p=0,0009$ ). Quando analisado o salto de melhor desempenho a diferença foi de $9,3 \mathrm{~cm}$ $(p=0,0001)$. Não foram encontradas diferenças significantes na altura de salto, entre os grupo TRF e FIS, através da análise do melhor salto $(p=0,97)$ ou da média de três saltos $(p=0,84)$.

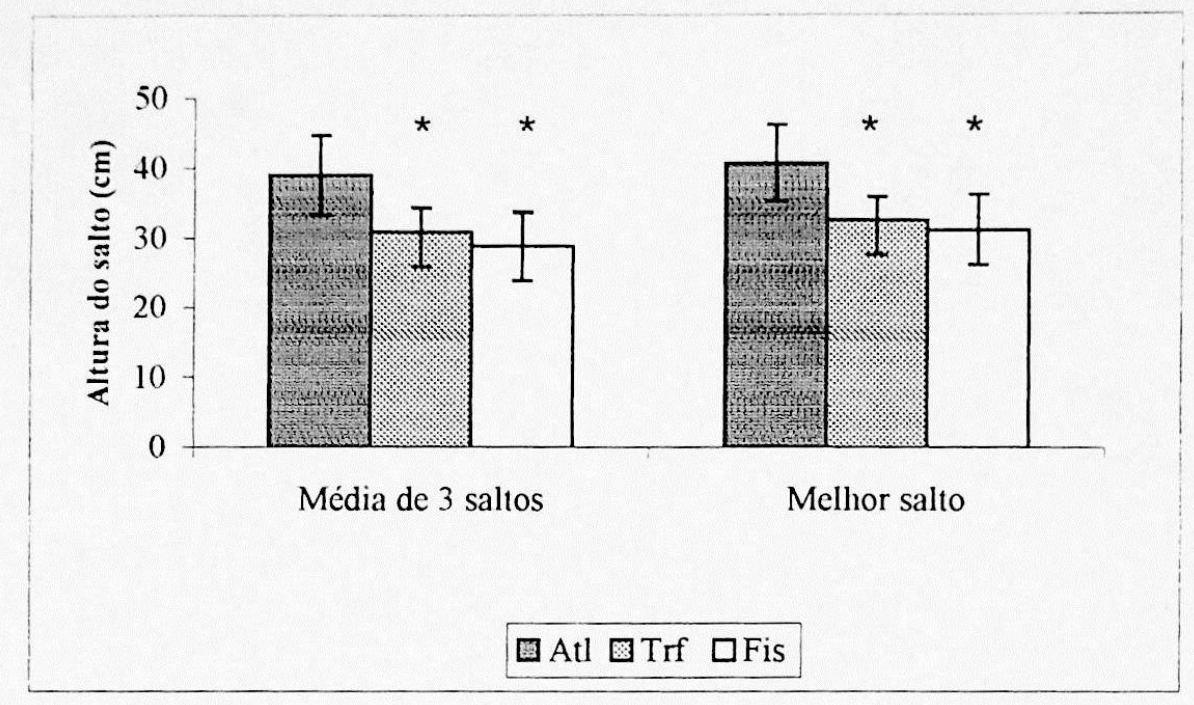

FIGURA 4 - Efeito principal do fator grupo, na AS, analisando a média de três saltos e o salto de melhor desempenho $(\mathrm{p} \leq 0,05)$ * Diferente do grupo de atletas

\subsection{Efeito principal do fator tempo na AS}

Foi verificado efeito principal significante do fator tempo na altura do salto vertical, na análise com a média de três saltos $(p=0,014)$. Os sujeitos saltaram em média $0,7 \mathrm{~cm}(\mathrm{p}=0,036)$ mais baixo, 4 minutos após a série inicial (pré) e, $1,1 \mathrm{~cm}$ mais baixo, 8 minutos após $(p=0,005)$. Não houve alterações significantes, na altura do salto, do $4^{\circ}$ para $08^{\circ}$ minuto $(\mathrm{p}=0,26)$. Quando analisado o salto de melhor desempenho, não houve efeito principal significante do fator tempo, na altura do salto vertical $(p=0,11)$. 


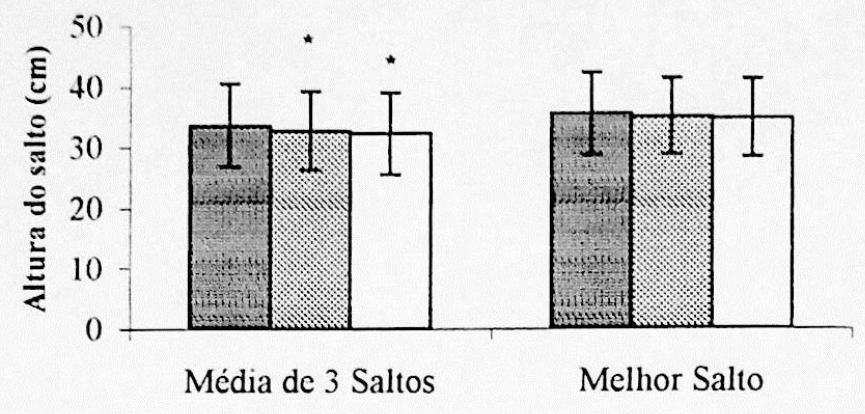

口pré estímulo $\mathbf{0} 4$ minutos após $\square 8$ minutos após

FIGURA 5 - Efeito principal do fator tempo, na altura AS, analisando a média de 3 saltos e o salto de melhor desempenho. * Diferença significante do pré-estímulo $(p \leq 0,05)$.

6.6 Efeito principal do fator tratamento na AS

A FIGURA 6 mostra o efeito principal do fator tratamento, na variável altura do salto. Não foi verificada qualquer alteração significante na altura do salto em razão da realização dos tratamentos (1CVIM ou 3CVIM) ou da situação controle, na análise da média de três saltos $(F=0,02 ; p=0,983)$ ou do salto de melhor desempenho $(F=0,04 ; p=0,96)$.

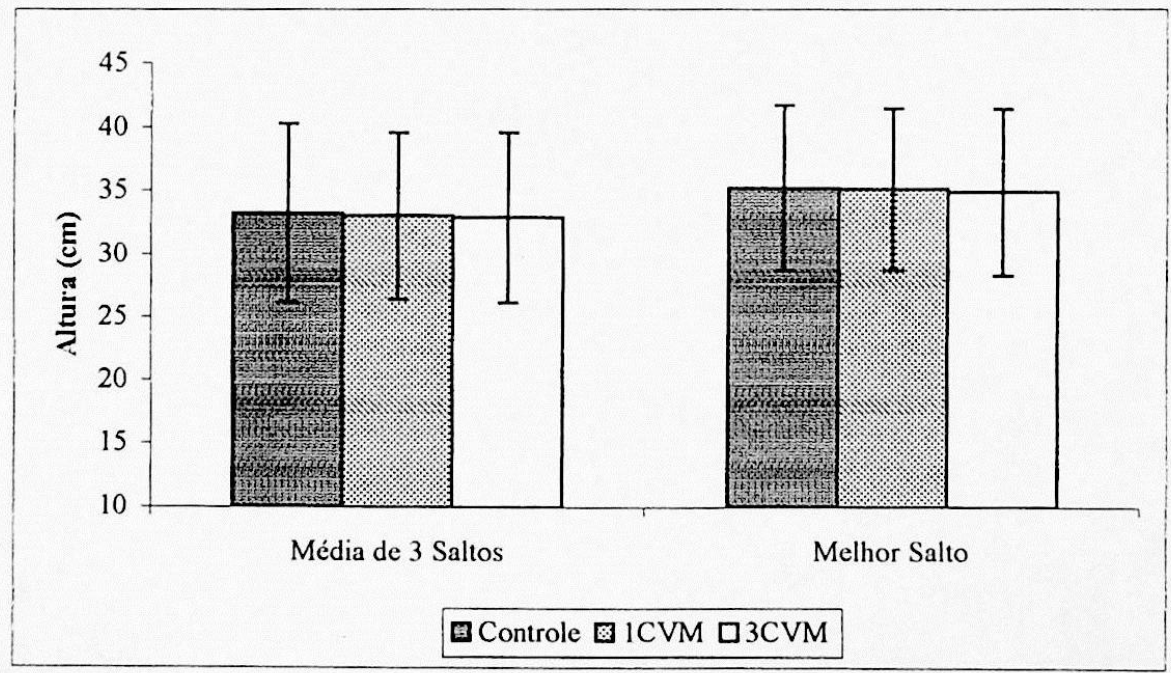

FIGURA 6 - Efeito principal do fator tratamento, na AS, analisando a média de três saltos e o salto de melhor desempenho. 
Dados referentes à variàvel dependente: taxa média de desenvolvimento de força (TDF média)

6.7 Efeito combinado dos fatores na TDF média.

Nas FIGURAS 7 e 8 são apresentados os efeitos dos diferentes tratamentos (ICVIM e 3CVIM), na TDF média, para os diferentes grupos, considerando-se, respectivamente, a análise do salto de melhor desempenho ou a média de desempenho de três saltos. Não se verificou diferença significante na TDF média do salto realizado antes do tratamento e após o mesmo ( 4 ou 8 minutos após), para nenhum dos grupos testados $(p \leq 0,05)$.

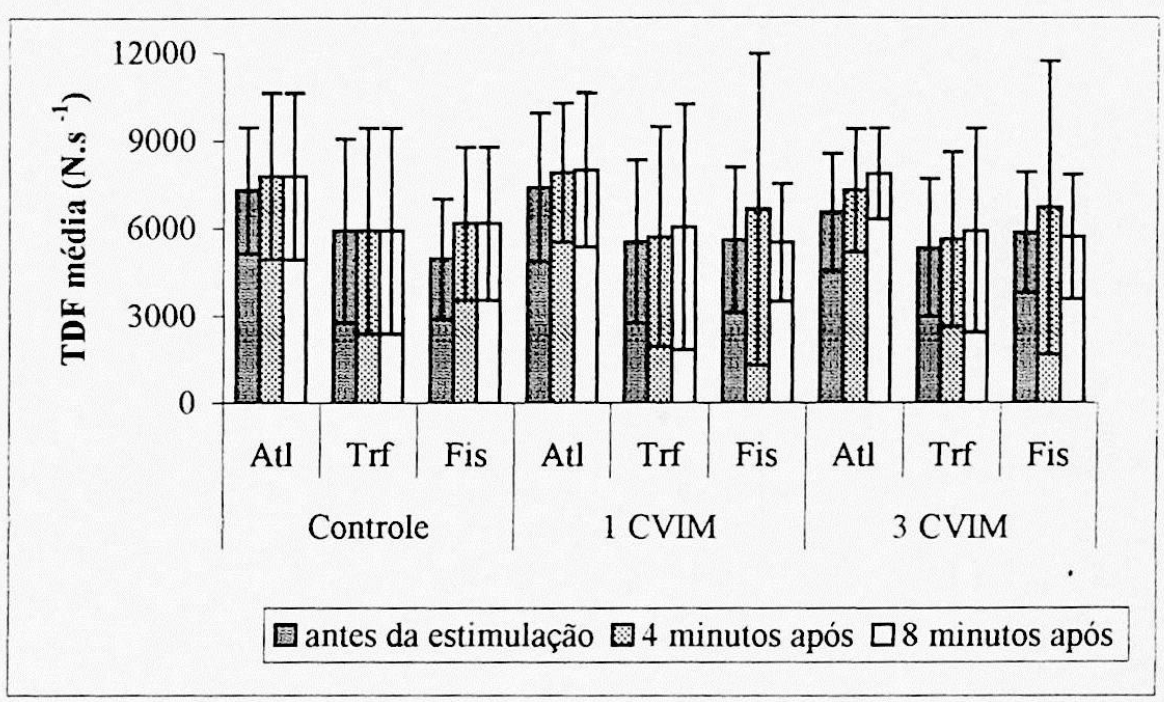

FIGURA 7 - Efeito combinado dos fatores, na TDF média, analisando o salto de melhor desempenho. 


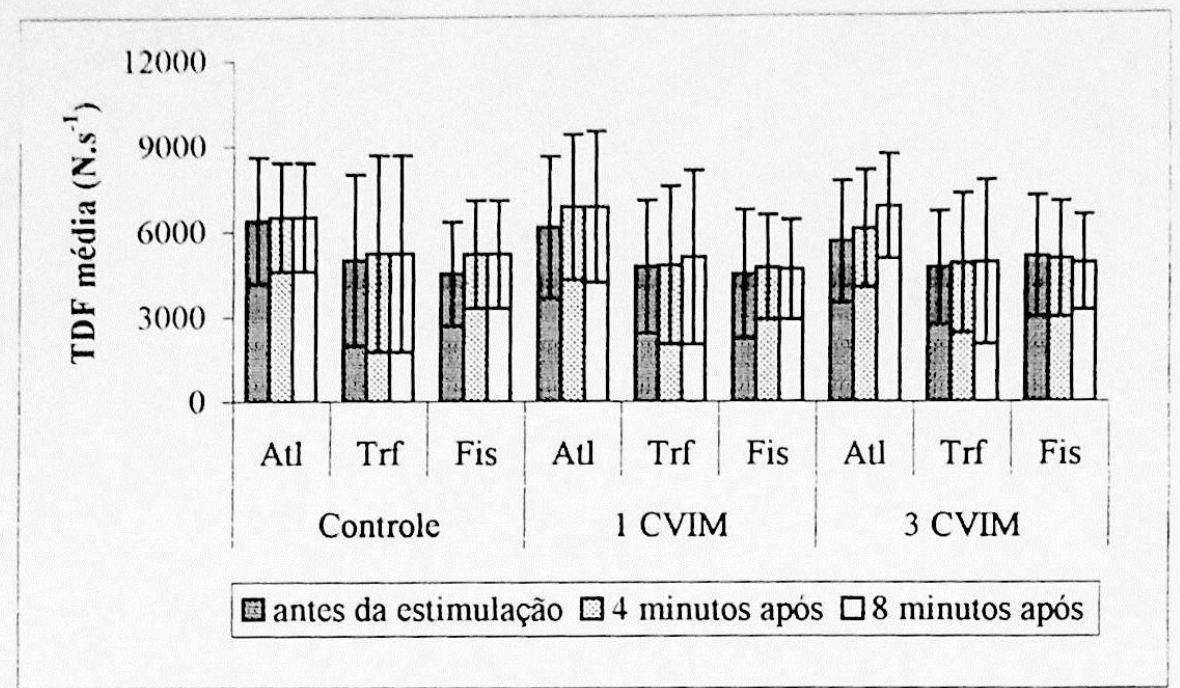

FIGURA 8 - Efeito combinado dos fatores, na TDF média, analisando a média de três saltos.

6.8 Efeito principal do fator grupo na TDF média.

A FIGURA 9 mostra que a TDF média não foi diferente entre os grupos analisando a média de três saltos $(\mathrm{F}=1,37 ; \mathrm{p}=0,27)$ ou o salto de melhor desempenho $(\mathrm{F}=1,88 ; \mathrm{p}=0,16)$.

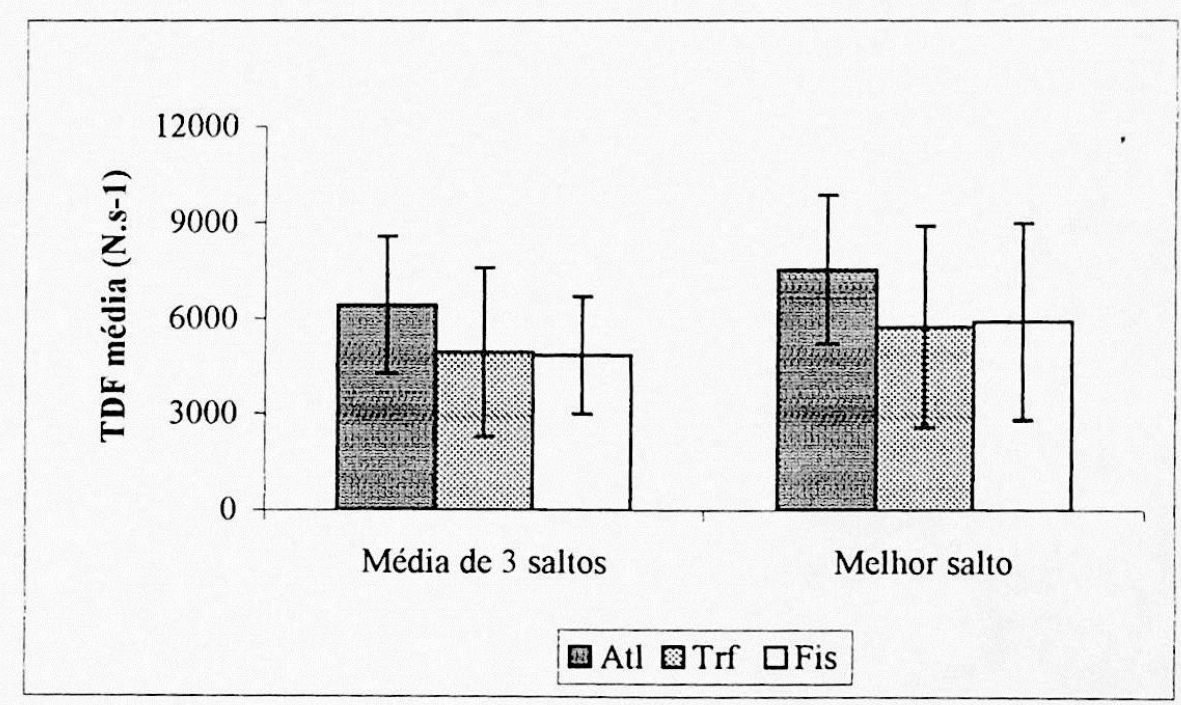

FIGURA 9 - Efeito principal do fator grupo, na TDF média, analisando a média de três saltos e o salto de melhor desempenho. 


\subsection{Efeito principal do fator tempo na TDF média}

Na FIGURA 10 verifica-se o efeito principal, do fator tempo, sobre a TDF média, quando analisada a média de três saltos $(F=5,43 ; p=0,005)$ ou o salto de melhor desempenho $(\mathrm{F}=4,21 \mathrm{p}=0,016)$. Quando a análise foi feita através da média de três saltos, verificou-se que, 4 minutos após o pré estimulo, a TDF média aumentou, em média $264,25 \mathrm{~N} \cdot \mathrm{s}^{-1}(\mathrm{p}=0,008)$. Ao $8^{\circ}$ minuto, após o pré estimulo, verificou-se aumento médio de $361,58 \mathrm{~N} \cdot \mathrm{s}^{-1}(\mathrm{p}=0,007)$. Não houve modificação significante da TDF média do $4^{\circ}$ para $\circ 8^{\circ}$ minuto $(p=0,51)$. Quando analisado o salto de melhor desempenho, verificou-se que, 4 minutos após o pré estimulo, a TDF média elevou-se $565,33 \mathrm{~N} . \mathrm{s}^{-1} \quad(\mathrm{p}=0,012)$. Ao $8^{\circ}$ minuto, após o pré estimulo, a TDF média apresentou um aumento, não significante, de $476,49 \mathrm{~N} \cdot \mathrm{s}^{-1}(\mathrm{p}=0,11)$. Do $4^{\circ}$ para o $8^{\circ}$ minuto não houve alteração significante da TDF média $(p=0,89)$.

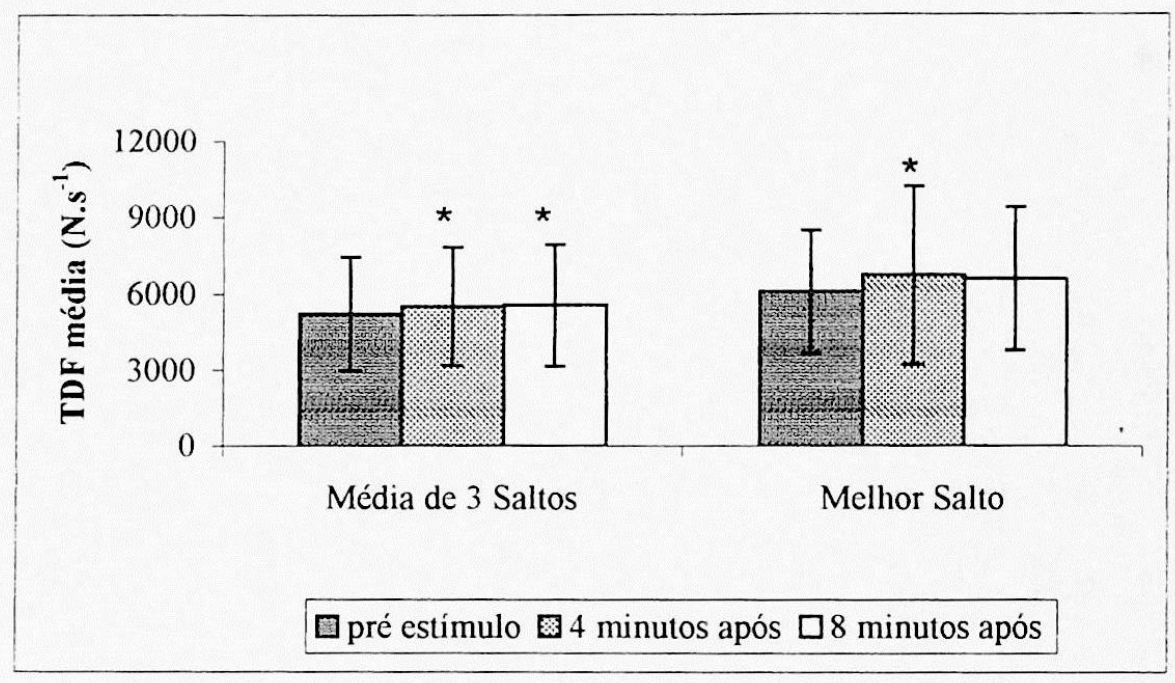

FIGURA 10- Efeito principal do fator tempo, na TDF média, analisando a média de três saltos e o salto de melhor desempenho. * Diferente do pré-estímulo $(p \leq 0,05)$.

6.10 Efeito principal do fator tratamento na TDF média.

A FIGURA 11 mostra o efeito principal do fator tratamento, na variável TDF média. Não foram encontradas diferenças significantes entre a TDF média nos três tratamentos (controle, 1CVIM ou 3CVIM), quando analisado através da média de três saltos $(\mathrm{F}=0,32$; $\mathrm{p}=0,72)$ ou através do salto de melhor desempenho $(\mathrm{F}=0,18 ; \mathrm{p}=0,83)$. 


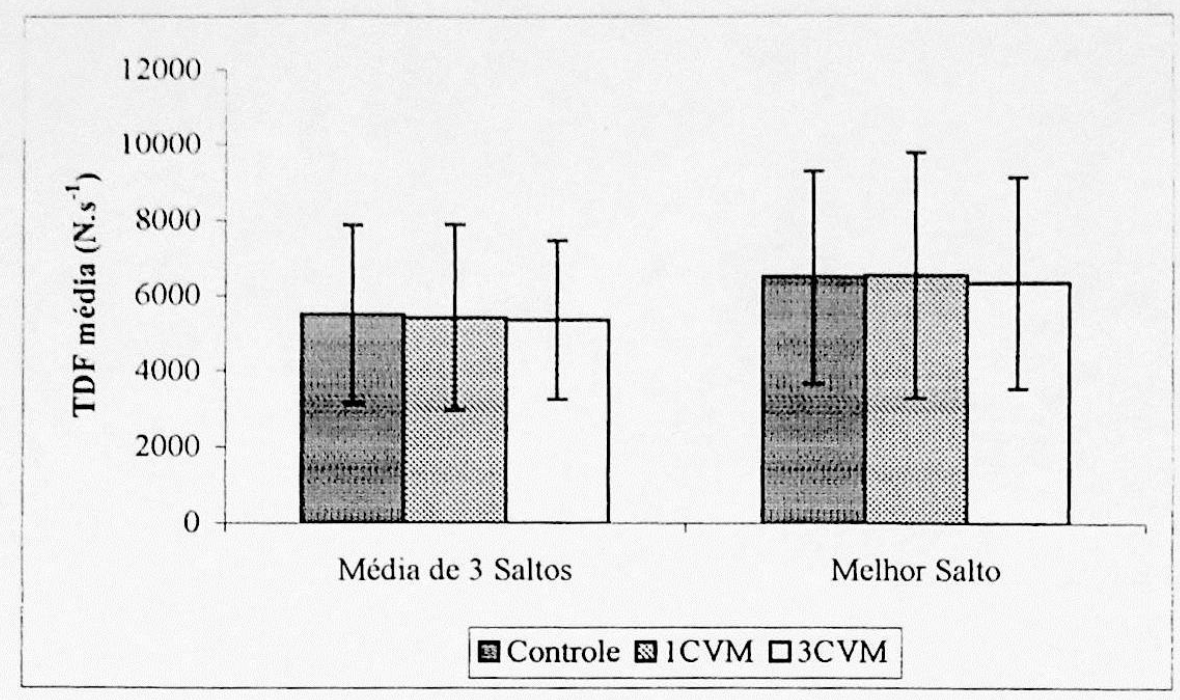

FIGURA 11 - Efeito principal do fator tratamento, na TDF média, analisando a média de três saltos e o salto de melhor desempenho.

Dados referentes à variável dependente: pico de força $(P F)$

\subsection{Efeito combinado dos fatores no PF.}

Nas FIGURAS 12 e 13 são apresentadas as alterações no pico de força em resposta aos tratamentos (1CVIM e 3CVIM) e a situação controle, para os três grupos. Na FIGURA 12, os dados são referentes a análise feita através da média de três saltos. Na FIGURA 13, ao salto de melhor desempenho. Os tratamentos não produziram alterações significantes no PF, para nenhum dos grupos $(p \leq 0,05)$. Isso se repetiu na análise através da média de três saltos e do salto de melhor desempenho. 


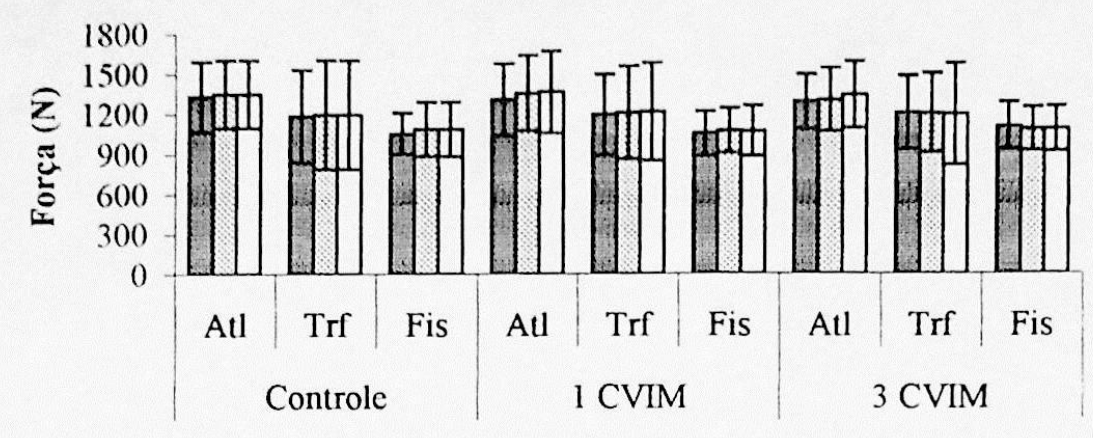

$\square$ antes da estimulação $\square 4$ minutos após $\square 8$ minutos após

FIGURA 12- Efeito combinado dos fatores, no PF, analisando a média de três saltos.

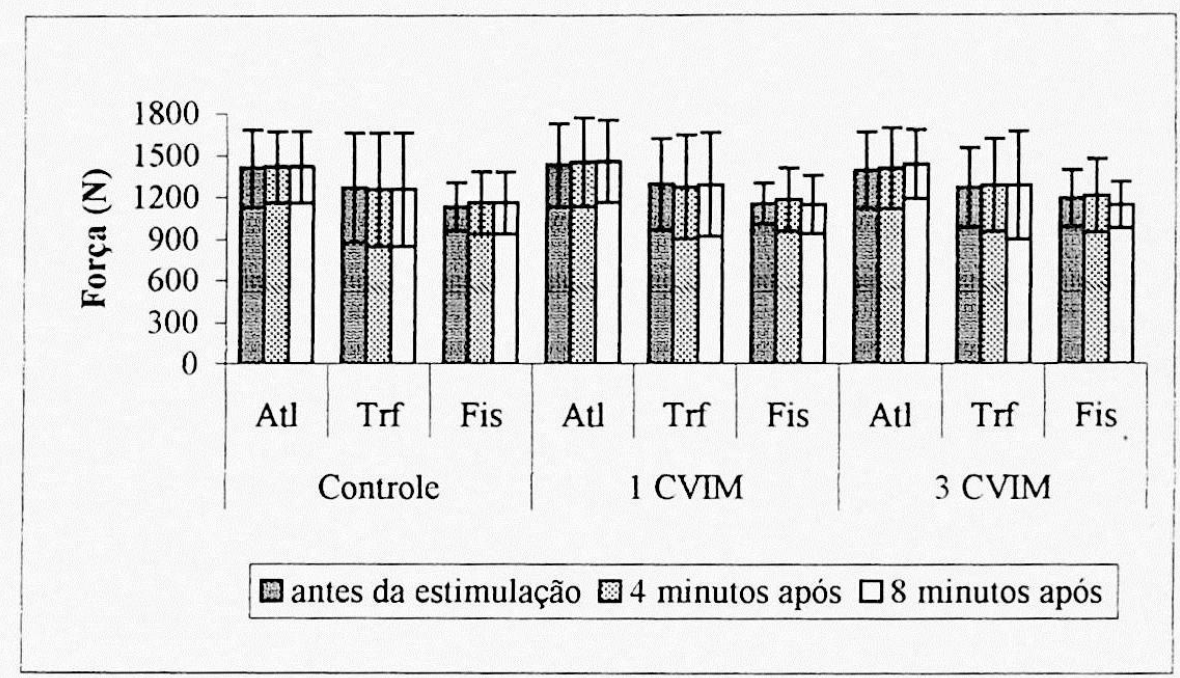

FIGURA 13- Efeito combinado dos fatores, no PF, analisando o salto de melhor desempenho.

\subsection{Efeito principal do fator grupo no PF.}

A FIGURA 14 mostra o efeito principal do fator grupo no PF. Não foram encontradas diferenças significantes entre o PF dos três grupos, quando analisada a média de três saltos $(F=1,91 ; p=0,16)$ ou o salto de melhor desempenho $(F=1,71 ; p=0,20)$. 


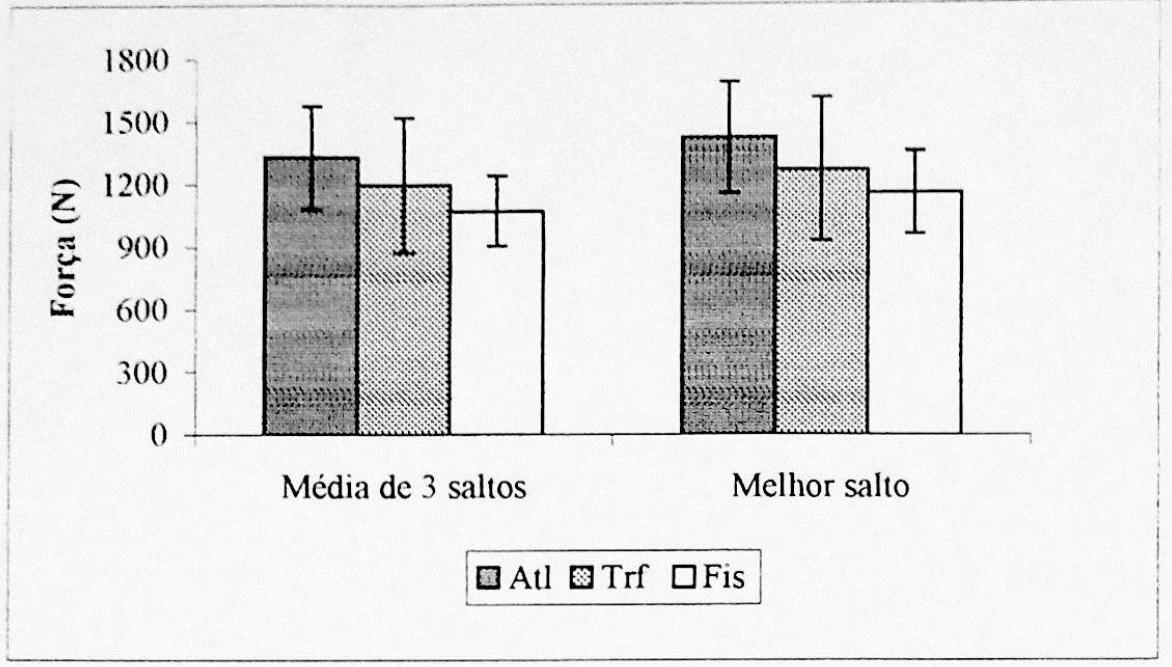

FIGURA 14- Efeito principal do fator grupo, na variável pico de força, analisando a média de três saltos e o salto de melhor desempenho.

\subsection{Efeito principal do fator tempo no PF.}

A FIGURA 15 mostra o efeito principal do fator tempo no PF. Não foram encontradas diferenças significantes entre o PF nos três tempos (pré, 4 e 8 minutos após), quando analisada a média de três saltos $(F=1,39 ; p=0,25)$ ou o salto de melhor desempenho $(F=1,21 ; p=0,81)$.

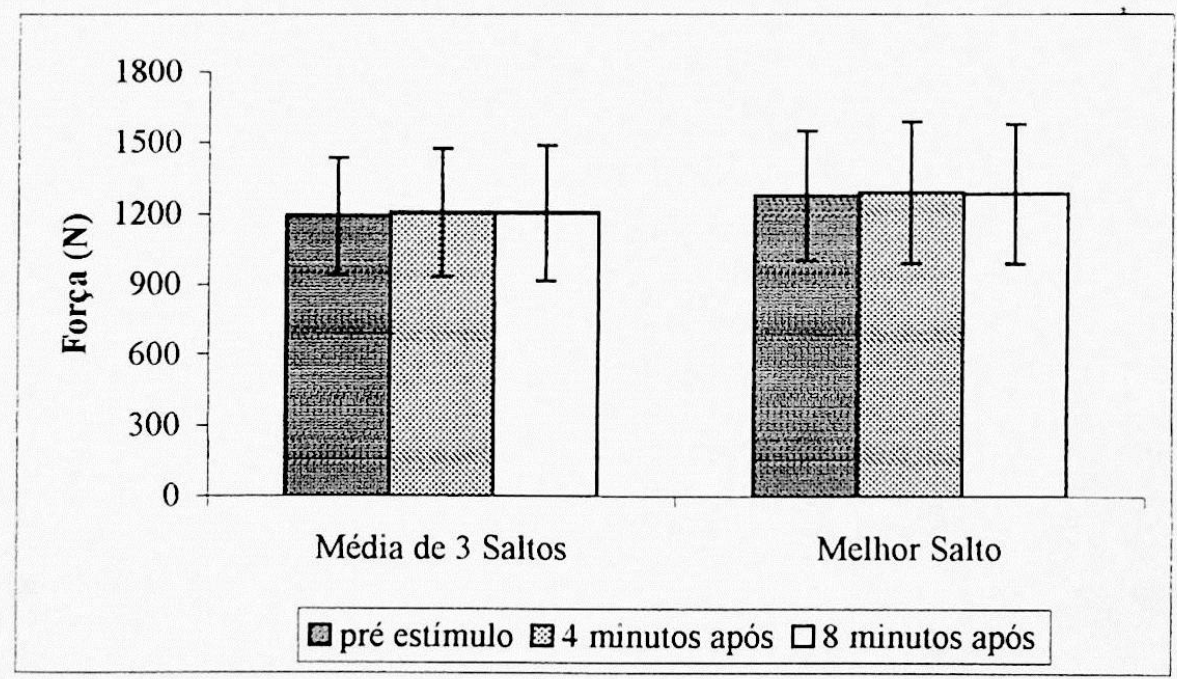

FIGURA 15- Efeito principal do fator tempo, no PF, analisando a média de três saltos e o salto de melhor desempenho. 
6.14 Efeito principal do fator tratamento no PF

A FIGURA 16 mostra o efeito principal do fator tratamento no PF. Não foram encontradas diferenças significantes no PF em razão dos tratamentos (1CVIM ou 3CVIM), ou da situação controle, quando analisada a média de três saltos $(F=0,48 ; p=0,61)$ ou o salto de melhor desempenho $(F=1,37 ; p=0,25)$.

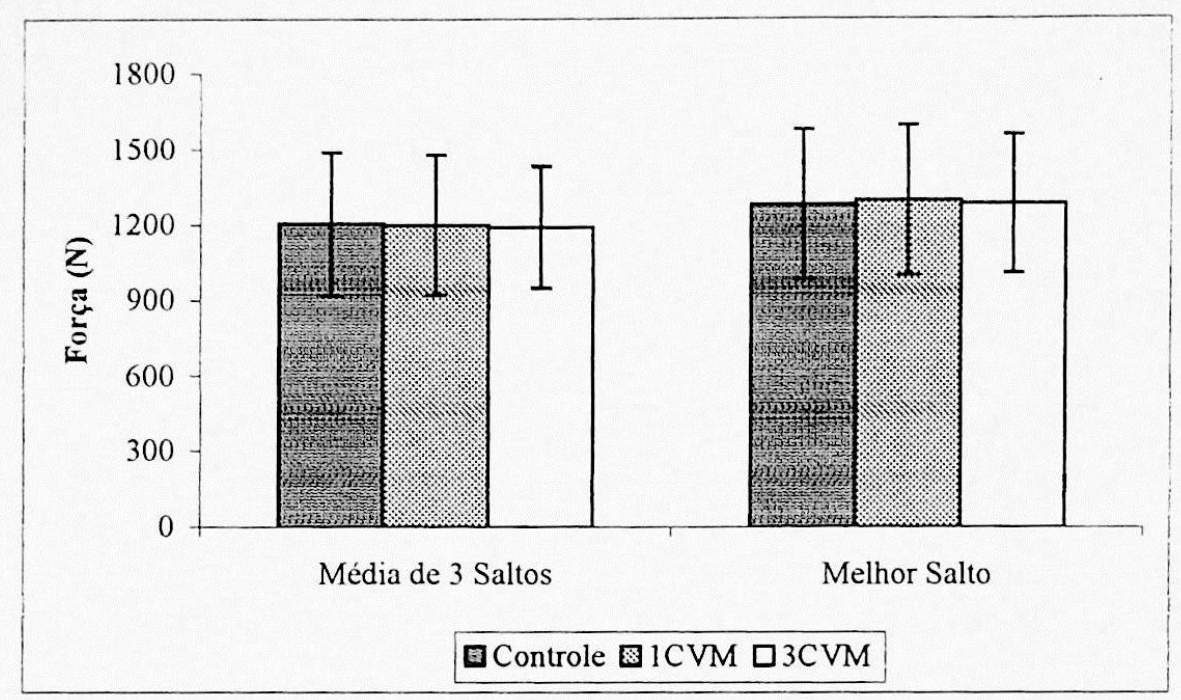

FIGURA 16- Efeito principal do fator tratamento, no PF, analisando a média de três saltos e o salto de melhor desempenho.

\section{DISCUSSÃO}

Ausência de diferença no nível de força, entre os grupos

Não foram encontradas diferenças significantes entre a força dinâmica máxima (FDM) dos grupos ATL $(364,5 \pm 115,1 \mathrm{Kg})$, TRF $(382,9 \pm 85,4 \mathrm{Kg})$ e FIS $(304,0 \pm 47,3 \mathrm{Kg})(\mathrm{F}=2$; $\mathrm{p}=0,157)$, medida através do teste de $1 \mathrm{RM}$.

Esperava-se que os grupos apresentassem diferentes níveis de FDM, já que possuiam diferentes experiências em treinamento de força. A expectativa era que os grupos TRF e ATL apresentassem superioridade no teste de 1RM em razão de estarem envolvidos com algum tipo de treinamento força, enquanto os sujeitos do grupo FIS não participavam desse tipo de treinamento havia pelo menos seis meses. 
O grupo ATL relatou treinar utilizando métodos e exercícios de treinamento que visam o aumento da potência muscular, entre eles o treinamento combinado e exercícios pliométricos como os saltos com sobrecarga e em profundidade. O treinamento combinado (realização de exercícios com cargas altas, iguais ou superiores a $80 \%$ de 1RM, imediatamente antes de exercicios com cargas baixas, em torno de 30\% de 1RM) assim como os exercicios pliométricos se mostraram eficientes para melhorar não somente o desempenho da potência muscular mas também da FDM (FATOUROS, JAMURTAS, LEONTSINI, TAXILDARIS, AGGELOUSIS, KOSTOPOULUS \& BUCKENMEYER, 2000; HAKKINEN, 1987; 1988; HARRIS, STONE, O'BRYANT, PROULX \& JOHNSON, 2000).

O treinamento do grupo TRF era orientado para o aumento da massa muscular e caracterizava-se pela realização de 6-9 séries de 8-12RM, divididas entre diferentes exercícios. Segundo as orientações do "American College of Sports Medicine" esse volume e intensidade de treinamento são adequados para promover o aumento da massa muscular e da FDM (KRAEMER, ADAMS, CAFARELLI, DUDLEY, DOOLY, FEIGUENBAUM, FLECK, FRANKLIN, FRY, HOFFMAN, NEWTON, POTTEIGER, STONE, RATAMES \& TRIPLETT-MCBRIDE, 2002)

Recentemente, CAMPOS, LUECKE, WENDELN, TOMA, HAGERMAN, MURRAY, RAGG, RATAMESS, KRAEMER e STARON (2002) testaram os efeitos de três diferentes regimes de treinamento, em indivíduos sem experiência prévia em treinamento de força. Os sujeitos foram divididos em quatro grupos que realizaram, durante oito semanas, os respectivos treinamentos utilizando os exercícios leg press, agachamento e cadeira extensora: grupo 1, 4 séries de 3-5RM; grupo 2, 3 séries de 9-11RM; grupo 3, 2 séries de 20-28RM; grupo controle, não se exercitou. Ao final do programa, os três grupos treinados melhoraram a FDM (1RM) nos três exercícios (leg press, agachamento e cadeira extensora) em relação ao desempenho pré-treino. Não foi encontrada diferença significante no desempenho do grupo controle. Os resultados desse estudo mostraram que o treinamento com cargas de intensidade variada podem produzir aumentos significantes na FDM após um periodo de oito semanas de treinamento. Portanto, poderia se esperar que o desempenho no teste de 1 RM (FDM) do grupo TRF fosse pelo menos superior ao do grupo FIS.

Os sujeitos do grupo FIS não participavam de qualquer tipo de treinamento de força havia pelo menos seis meses. Esse grupo, no entanto, estava envolvido com diferentes tipos de 
atividades fisicas como, por exemplo, jogos esportivos coletivos, corrida, ciclismo estacionário e natação.

Em razão de suas diferentes experiências em treinamento, acreditávamos que haveria diferença entre a FDM dos grupos. Pode ser que o desempenho dos sujeitos tenha sido influenciado pela falta de experiência com o teste de IRM. Em um estudo recente, SCOTT e DOCHERTY (2004) realizaram quatro sessões de familiarização antes de determinar a carga máxima no teste de 5RM, no exercício agachamento. Os sujeitos envolvidos no estudo tinham, no mínimo, um ano de experiência com o exercício de agachamento e possuiam experiência no teste de IRM. Apesar de possuírem um bom nivel de experiência com o exercício utilizado e com o teste de 1RM, a FDM dos sujeitos sofreu um aumento médio de $20 \%$ ao longo das quatro sessões de familiarização

Um outro estudo, realizado por PLOUTZ-SNYDER e GIAMIS (2001), também demonstrou que a determinação consistente da FDM, através do teste de 1RM, somente é possível após a realização de múltiplas sessões de familiarização ao teste. Neste estudo, mulheres jovens, inexperientes em treinamento de força e no teste de $1 \mathrm{RM}$, precisaram, em média, de 3,6 \pm 0,6 sessões (variação entre duas a cinco sessões) de familiarização para atingir uma medida consistente de FDM, em um exercício de fácil execução como a extensão dos joelhos na posição sentada. Por outro lado, mulheres idosas precisaram, em média, de $8,8 \pm$ 0,6 sessões (variação entre sete e dez sessões) para estabilizarem o desempenho no teste de 1RM. Em termos absolutos, não houve diferença significante entre os grupos na melhora do desempenho no teste. Jovens e idosas tiveram, respectivamente, um aumento de $14,3 \pm 5,6$ e $13,0 \pm 2,2 \mathrm{Kg}$, da primeira para a última sessão de familiarização. Contudo, quando considerados os ganhos de força em termos relativos ao valor inicial, o desempenho do teste foi significantemente diferente entre os dois grupos. Entre as jovens, o aumento médio foi de $12 \%$ em relação ao valor inicial, e entre as idosas, de $22 \%$.

Em nosso estudo, tanto os sujeitos do grupo ATL como os do grupo TRF (experientes em treinamento de força), relataram ser incomum utilizar o leg press como exercício de treinamento. Os sujeitos do grupo ATL relataram serem habituados ao teste de 1RM, pois, freqüentemente, o realizavam para determinar a carga dos exercicios de treinamento. Contudo, sempre utilizando o exercício de agachamento. Por outro lado, apenas dois sujeitos dos grupos TRF e FIS já haviam feito o teste de 1RM, entretanto, utilizando outros exercícios que não o 
leg press. Além disso, em nosso estudo não foi realizada nenhuma sessão de familiarização ao teste de IRM, mas somente ao exercicio leg press. Portanto, é possivel que a FDM dos sujeitos dos três grupos tenha sido subestimada, em razão de não havermos realizado sessões de familiarização ao teste de IRM.

No estudo de PLOUTZ-SNYDER e GIAMIS (2001) o número necessário de sessões de familiarização e a magnitude do aumento do desempenho no teste ao longo das sessões, foram influenciados pela idade e, possivelmente, pelo nível inicial de força dos grupos testados, já que, as mulheres idosas, mais fracas inicialmente, experimentaram uma maior evolução no desempenho do teste. Assim, supõe-se que a realização de sessões de familiarização, em nosso estudo, poderia induzir aumentos de desempenho de diferentes magnitudes em cada grupo, em razão de suas respectivas experiências e histórias de treinamento de força.

É importante destacar que a avaliação da FDM teve como único propósito caracterizar a mostra estudada, e por isso, as supostas falhas na sua realização não interferiram no objetivo principal do estudo.

Efeito principal do fator grupo na altura do salto

Foi verificado efeito principal significante do fator grupo na altura do salto. O grupo ATL saltou $8,2 \mathrm{~cm}(\mathrm{p}=0,0027)$ e $8,1 \mathrm{~cm}(\mathrm{p}=0,0013)$ mais alto que o grupo TRF e $8,7 \mathrm{~cm}$ $(p=0,0009)$ e $9,3 \mathrm{~cm}(p=0,0001)$ que o grupo FIS, quando a análise foi feita por meio da média de três saltos e do salto de melhor desempenho, respectivamente (FIGURA 4). Entretanto, não houve diferença significante na altura do salto entre os grupos TRF e FIS, através da análise da média de três saltos $(p=0,84)$ ou do melhor salto $(p=0,97)$. O melhor desempenho do grupo ATL no salto vertical pode estar relacionado com características fisiológicas musculares e com o tipo de treinamento realizado por esse grupo.

Apesar de não terem sido realizadas biópsias musculares, é conhecido que atletas de alto nível em modalidades de força explosiva possuem predominância de fibras musculares tipo II (TESCH \& KARLSSON, 1985). Esse tipo de fibra muscular se caracteriza pela maior capacidade de produção de tensão e velocidade de encurtamento, o que possibilita um melhor desempenho em atividades de caráter explosivo (COYLE, COSTIL \& LESMES, 1978). 
O treinamento de força para o desenvolvimento da potência muscular promove adaptações neurais como o aumento da freqüência de disparos de impulsos neurais e aumento da sincronização de descarga das unidades motoras (AAGAARD, SIMONSEN, ANDERSEN, MAGNUSSON \& DYHRE-POULSEN, 2002). Estas adaptações, sobretudo, favorecem o aumento da TDF que por sua vez tem grande influência sobre o desempenho de atividades como o salto vertical (BAKER, 2001; SCHMIDTBLEICHER, 1992; SEMMLER, 2002). Outro tipo de adaptação neural promovida pelo treinamento de força, que também pode favorecer a execução de movimentos de potência, é o aumento do "stiffness" muscular. O aumento do "stiffness" muscular está relacionado com a atividade dos órgãos tendinosos de Golgi (OTGs) e dos fusos musculares. Os primeiros atuam diminuindo o "stiffness" muscular quando o músculo é submetido a sobrecargas excessivas. Os fusos musculares atuam aumentando o "stiffness" quando o músculo é rapidamente alongado. O aumento do "stiffness" muscular pode ocorrer em resposta a inibição da atividade dos OTGs e ao aumento da sensibilidade dos fusos musculares, ou ainda, pela combinação de ambos. Segundo KOMI (1986), exercícios que utilizam o ciclo alongamento-encurtamento, como por exemplo, o salto vertical com contramovimento, podem se beneficiar dessa adaptação promovida pelo treinamento de força. Durante a fase excêntrica do salto com contramovimento a musculatura extensora do joelho é submetida a uma grande sobrecarga que produz o alongamento rápido da musculatura. Uma vez que a atividade dos OTGs é inibida em sujeitos treinados em força, essa sobrecarga não será suficiente para diminuir o stiffness muscular nesses indivíduos. Além disso, o aumento da sensibilidade dos fusos, também ocasionada pelo treinamento de força, permite que neurônios sensoriais Ia sejam ativados mais facilmente, aumentando o suporte neural para os motoneurônios $\alpha$ que inervam a musculatura agonista (extensores do joelho) e ao mesmo tempo inibindo a musculatura antagonista, favorecendo uma contração muscular mais potente na fase concêntrica do salto (KANDEL, SCHWARTZ \& JESSELL, 2000; KOMI, 1996).

Alguns estudos mostraram existir correlação entre o nível de FDM avaliada no teste de IRM e o desempenho no salto vertical (BARKER, WYATT, JOHNSON, STONE, O'BRYAN, POE \& KENT, 1993; FRY \& KRAEMER, 1991). Isto significa que a força máxima pode, ao menos parcialmente, explicar a altura atingida no salto vertical (DOWLING \& VAMOS, 1993). Não seria surpresa se o grupo TRF apresentasse melhor desempenho que o grupo FIS, pois, uma vez que eram praticantes de treinamento de força seria esperado que 
tivessem maior nivel de FDM que o grupo FIS (não praticantes de treinamento de força). No entanto, não houve diferença na altura do salto entre esses dois os grupos. Este resultado é coerente se considerarmos que os grupos TRF e FIS não apresentaram diferenças significantes no teste de IRM (FIGURA 1). No entanto, deve ser lembrado que o teste de IRM pode não ter representado uma medida confiável da FDM, em razão dos motivos previamente expostos. Assim, outro fator deveria justificar o desempenho semelhante na altura do salto vertical entre os grupos TRF e FIS. Pode ser que uma possível vantagem do grupo TRF sobre o grupo FIS tenha sido compensada pelo fato dos sujeitos do grupo FIS serem praticantes de atividades esportivas em que o salto vertical é bastante realizado, como o futebol e o voleibol. O envolvimento nesse tipo de atividade pode ter beneficiado os sujeitos do grupo FIS uma vez que os sujeitos do grupo TRF eram menos familiarizados ao padrão de movimento do salto.

Efeito principal do fator tempo na altura do salto vertical e na TDF média

Quando analisado através da média de três saltos houve efeito principal significante do fator tempo na altura do salto vertical $(\mathrm{p}=0,04)$ (FIGURA 5). Os sujeitos saltaram em média $0,7 \mathrm{~cm}(\mathrm{p}=0,036)$ e $1,1 \mathrm{~cm}(\mathrm{p}=0,005)$ mais baixo, respectivamente, ao $4^{\circ}$ e $8^{\circ}$ minutos após a série inicial (pré). A altura do salto diminuiu em média $0,3 \mathrm{~cm}$ do $4^{\circ}$ para o $8^{\circ}$ minuto, porém, esta diferença não foi significante $(p=0,26)$

Para qualquer diminuição observada no desempenho é tentador recorrer a instalação da fadiga como explicação. No entanto, parece que a diminuição da altura do salto ao longo do tempo não poderia ser explicada desta maneira. Quando analisamos a FIGURA 10, que se refere ao efeito principal do fator tempo na TDF média, verificamos que houve um aumento significante nesta variável ao $4^{\circ}\left(264,25 \mathrm{~N} . \mathrm{s}^{-1} ; \mathrm{p}=0,008\right)$ e $8^{\circ}$ minutos $\left(361,58 \mathrm{~N} . \mathrm{s}^{-1} ; \mathrm{p}=0,007\right)$, em relação ao pré-teste, quando analisada a média de três saltos. Também houve um aumento significante ao $4^{\circ}$ minuto $\left(565,33 \mathrm{~N} . \mathrm{s}^{-1} ; \mathrm{p}=0,012\right)$, após o pré-teste, quando analisado o melhor salto. Caso os sujeitos estivessem desenvolvendo fadiga, não poderia ser verificado aumento da TDF média nestes intervalos.

A altura atingida no salto vertical com contramovimento é dependente da magnitude do impulso produzido durante a fase concêntrica do salto. Quanto maior o impulso, maior a altura atingida. Uma vez que, o impulso é o produto de uma força pelo tempo de aplicação desta, é 
possivel se produzir o mesmo impulso, e portanto, a mesma altura de salto, modulando a magnitude da força produzida ou seu tempo de aplicação.

$\mathrm{O}$ aumento da TDF média, em função do fator tempo, nos mostra que os sujeitos alteraram sua estratégia para produzir impulso. Ou seja, a produção de força passou a ser mais rápida ao $4^{\circ}$ e $8^{\circ}$ minutos após o pré-teste. Este aumento da TDF média poderia se traduzir em um aumento da altura do salto, desde que, o tempo para aplicação de força não fosse diminuído. Não analisamos este dado, no entanto, como mostrado na FIGURA 15, o fator tempo não produziu qualquer alteração no pico de força. Uma vez que a TDF média aumentou, o pico de força também teria aumentado, caso o tempo para aplicação de força não tivesse diminuído. Portanto, como não houve alteração no pico de força, podemos especular que o tempo para aplicação de força diminuiu ao mesmo tempo em que a TDF média aumentava. Assim, apesar da TDF média ter aumentado nos pós-testes, o que poderia implicar numa maior produção de força, o tempo de duração da aplicação da força durante o salto parece ter diminuído. Isto levou a produção de um impulso menor ao $4^{\circ}$ e $8^{\circ}$ minutos após o pré-teste, o que explica a diminuição da altura do salto nestes intervalos.

\section{Efeito dos tratamentos na altura do salto}

Nas FIGURAS 2 e 3, verifica-se que a altura do salto vertical com contramovimento não sofreu qualquer alteração significante, em função da realização prévia de 1CVIM ou 3CVIM. Também não houve alteração significante, na altura do salto, quando foram realizadas as sessões controle. Esses resultados foram semelhantes para os três grupos, analisando o salto de melhor desempenho ou a média de três saltos. Ou seja, o efeito de potencialização da força explosiva, não se manifestou na altura do salto, independentemente do tipo de experiência do sujeito em treinamento de força, ou do volume de exercícios de força, utilizados para estimulála.

Um estudo recente de BATISTA et al. (2003) também não produziu modificação significante na altura do salto com contramovimento, após os sujeitos fisicamente ativos, realizarem 3 CVIM de $5 \mathrm{~s}$ no leg press. Contudo, os resultados desses dois estudos são contrastantes com o estudo de GÜLLICH e SCHMIDTBLEICHER (1996), em que a altura do salto vertical com contramovimento teve uma melhora momentânea, de até $3 \%$, depois que os sujeitos atletas realizaram 1, 3 ou 5 CVIM de 5 s de duração no leg press. Não se pode afirmar, 
portanto, que CVIM de $5 \mathrm{~s}$ de duração sejam ineficientes em desencadear o efeito de potencialização da altura do salto. Além disso, CVIM se mostraram eficientes em desencadear a potencialização também em outros tipos de exercícios envolvendo membros superiores e inferiores (GÜLLICH \& SCHMIDTBLEICHER, 1996; HAMADA et al., 2000).

Em alguns estudos a potencialização mostrou-se relacionada com o nível da FDM dos sujeitos. Por exemplo, YOUNG, JENNER e GRIFFITHS (1998) verificaram que sujeitos mais fortes tinham os maiores aumentos na altura do salto após realizarem 1 x 5RM no agachamento. DUTHIE, YOUNG e AITKEN (2002) demonstraram que os sujeitos mais fortes aumentaram o pico de força produzido durante o salto vertical com carga adicional (30\% IRM), após realizarem 1 x $3 \mathrm{RM}$ no agachamento. Inversamente, os sujeitos mais fracos mostraram uma tendência a diminuição no pico de força. No estudo de GOURGOULIS et al. (2003) a realização de 2 repetições com cada uma das cargas de 20, 40, 60, 80 e 90\% de 1RM, produziu um aumento agudo da altura do salto vertical de $4,01 \%$ nos sujeitos que suportaram mais de $160 \mathrm{Kg}$ no teste de 1RM. Por sua vez, os sujeitos que suportaram menos que $160 \mathrm{~kg}$ nesse teste, aumentaram apenas $0,42 \%$ seu desempenho após o exercício estimulador. É preciso mencionar, no entanto, que estatisticamente o aumento entre os dois grupos não foi significante. Diferentemente, outros estudos não verificaram potencialização do desempenho, mesmo entre os sujeitos mais fortes ( $\mathrm{KOCH}$ et al., 2003; SCOTT \& DOCHERTY, 2004) mostrando que a relação entre a FDM e a potencialização é bastante controversa e obscura.

Em nosso estudo, os grupos testados eram formados por sujeitos com diferentes experiências em treinamento de força. Supostamente, essa diferença na experiência em treinamento de força deveria produzir niveis diferentes de FDM e força explosiva entre os grupos. Segundo o resultado do teste de 1RM, os três grupos possuíam nivel semelhante de FDM (FIGURA 1). No entanto, considerando o desempenho de cada grupo na altura do salto vertical, podemos dizer que o grupo ATL mostrou ter melhor desempenho da força explosiva em comparação aos grupos TRF e FIS (FIGURA 4).

Em alguns estudos a potencialização se manifestou restritamente em indivíduos atletas experientes em treinamento de força e potência (DUTHIE, YOUNG \& AITKEN, 2002; GÜLLICH \& SCHMIDTBLEICHER, 1996). Considerando que a relação entre o nível de força máxima e o fenômeno de potencialização não está clara, pode-se supor que adaptações promovidas pelo treinamento de força explosiva poderiam interferir no fenômeno de potencialização. 
Em razão do teste de IRM não mostrar diferença significante entre o nivel de FDM dos très grupos não se pode fazer inferências a respeito da relação entre o nivel de força máxima e potencialização. Uma vez que as CVIM não alteraram o desempenho da altura do salto em nenhum dos grupos, podemos também afirmar que o nível da força explosiva não influenciou a potencialização do salto vertical. Além disso, pode-se concluir que o tipo de experiência em treinamento de força não interferiu na manifestação da potencialização.

Acredita-se que a eficiência dos exercícios de força em provocar potencialização seja influenciada pela intensidade e pelo volume dos exercícios estimuladores. Autores que defendem que os exercícios de estimulação devem ser de alta intensidade, justificam que a potencialização depende da ativação de grande quantidade de fibra tipo II. Isto porque, as fibras tipo II são mais suscetiveis a fosforilação da miosina RCL, um provável mecanismo fisiológico que suportaria a potencialização da força explosiva (GRANGE et al., 1998). Contudo, os resultados de alguns estudos colocam em dúvida a necessidade da atividade condicionante ser de alta intensidade. Por exemplo, BAKER (2003) mostrou que uma série com 65\% de 1RM, no exercício supino, é um estimulo de intensidade suficiente para potencializar o desempenho da força explosiva de membros superiores. Outros estudos mostraram que o desempenho no salto vertical também aumentou quando essa atividade era precedida por exercícios de força utilizando cargas submáximas como 75-85\% de 4RM (RADCLIFFE \& RADCLIFFE, 1996) e uma série de 5RM (YOUNG et al., 1998). Em nosso estudo foram realizadas séries de contrações isométricas máximas de cinco segundos de duração. Conhecidamente, contrações isométricas máximas produzem maior torque muscular que contrações dinâmicas máximas. Assim, não se pode atribuir à intensidade do exercício, utilizado como estímulo em nosso estudo, o insucesso em produzir um aumento agudo na altura do salto. GÜLLICH e SCHMIDTBLEICHER (1996) demonstraram que contrações isométricas máximas de cinco segundos de duração induziam aumentos de até $3 \%$ na altura do salto de sujeitos atletas. Assim, apesar do protocolo de estimulação utilizado nesse estudo estar de acordo com o proposto na literatura, a não ocorrência da potencialização foi provavelmente conseqüência da fadiga causada pela combinação do volume de saltos realizados para avaliar a potencialização com a intensidade da atividade estimuladora. 

CONCLUSÕES

- A realização de 1 ou 3CVIM não induziu alteração significante na altura, taxa média de desenvolvimento de força e pico de força do salto vertical com contramovimento. Portanto, não seria útil incluir este tipo de exercício de força na rotina de aquecimento, visando tais beneficios, pelo menos para a amostra testada;

- A manifestação da potencialização do desempenho do salto não foi dependente do volume de exercício de força realizado no aquecimento, pelo menos, quando este é composto por contrações voluntárias isométricas máximas de cinco segundos;

- A manifestação da potencialização do desempenho do salto não foi dependente do tipo de experiência do sujeito em treinamento de força. 


\section{REFERÊNCIAS}

AAGAARD, P.; SIMONSEN, E.B.; ANDERSEN, J.L.; MAGNUSSON, P.; DYHREPOULSEN, P. Increase rate of force development and neural drive of human skeletal muscle following resistance training. Journal of Applied Physiology, Bethesda, v.93, p. 1318-1326, 2002

BAKER, D. A series of studies on the training of high-intensity muscle power in rugby league football players. Journal of Strength and Conditioning Research, Champaign, v.15, n.2, p. 198-209, 2001.

Acute effect of alternating heavy and light resistances on power output during upperbody complex power training. Journal of Strength and Conditioning Research, Champaign, v.17, n.3, p.493-497, 2003

BARKER, M.; WYATT, T.J.; JOHNSON, R.L.; STONE, M.H.; O'BRYAN, H.S.; POE, C.; KENT, M. Performance factors, psychological assessment, physical characteristics, and football playing ability. Journal of Strength and Conditioning Research, Champaign, v.7, n. 4, p. 224-233, 1993

BATISTA, M.A.B.; COUTINHO, J.P.A.; BARROSO, R.; TRICOLI, V. Potencialização: a Influência da contração muscular prévia no desempenho da força rápida. Revista Brasileira de Ciência e Movimento, Brasília, v. 11, n.2, p.07-12, 2003.

BELANGER, A.Y., MCCOMAS, A. J. Contractile properties of human skeletal muscle in childhood and adolescence. European Journal of Applied Physiology, Berlin, v.58, p.563$567,1989$.

BISHOP, D. Warm up I: potential mechanisms and the effects of passive warm up on exercise performance. Sports Medicine, Auckland, v.33, n.6, p.439-454, 2003 a. 
Warm up II: performance changes following active warm up and how to structure the warm up. Sports Medicine, Auckland, v.33, n. 7, , p.483-498, 2003 b.

BROWN, L.E.; WEIR, J.P. ASEP Procedures recommendation I: accurate assessment of muscular strength and power. Journal of Exercise Physiology, Duluth, v.4, n.3, p.1-21, 2001

CAMPOS, G.E.R.; LUECKE, T.J.; WENDELN, H.K.; TOMA, K.; HAGERMAN, F.C.; MURRAY, T.F.; RAGG, K.E.; RATAMESS, N.A.; KRAEMER, W.J.; STARON, R. Muscular adaptations in response to three different resistance-training regimens: specificity of repetition maximum training zones. European Journal of Applied Physiology, Berlin, v.88, p. $50-60,2002$.

CHIU, L.Z.; FRY, A.C.; WEISS, L.W.; SCHILLING, B.K.; BROWN, L.E.; SMITH, S.L. Postactivation potentiation response in athletic and recreationally trained individuals. Journal of Strength and Conditioning Research, Champaign, v. 17, n.4, p.671-677, 2003.

CORNWELL, A.; NELSON, A.G.; HEISE, G.D.; SIDAWAY, B. Accute effects of passive musle stretching on vertical jump performance. Journal of human movement studies, Edinburgh, v.40, p.307-324, 2001.

COYLE, E.F.; COSTIL, D.L.; LESMES, G.R. Leg extension power and muscle fiber composition. Medicine and Science in Sports and Exercise, Madison, v. 11, p. 12-15, 1978

DOWLING, J.J.; VAMOS, L. Identification of kinetic and temporal factors related to vertical jump performance. Journal of Applied Biomechanics, Champaign, v.9, p.95-110, 1993.

DUTHIE, G.M.; YOUNG, W.B.; AITKEN, D.A. The acute effects of heavy loads on jump squat performance: an evaluation of the complex and contrast methods of power development. Journal of Strength and Conditioning Research, Champaign, v. 16, n.4, p. 530-538, 2002. 
EBBEN, W.P.; JENSEN, R. L.; BLACKARD, D.O. Electromyographic and kinetic analysis of complex training variables. Journal of Strength and Conditioning Research, Champaign, v. 14, n. 4, p. $451-456,2000$.

ENOKA, R.M. Neuromechanical basis of kinesiology, Champaign, Human Kinetics, 1988.

EVANS, A.K.; DURHAM, M.P.; HODGKINS, T.D.; SINCLAIR, D.R.; ADAMS, K.J. Acute effects of bench press on power output during a subsequent ballistic bench throw. Medicine and Science in Sports and Exercise (supplement), Madison, v.33, n.5, p.S325, 2001.

FATOUROS, I.G.; JAMURTAS, A.Z.; LEONTSINI, D.; TAXILDARIS, K.; AGGELOUSIS, N.; KOSTOPOULUS, N.; BUCKENMEYER, P. Evaluation of plyometric exercise training, weight training, and their combination on vertical jumping performance and leg strength. Journal of Strength and Conditioning Research, Champaign, v. 14, n.4, p.470-476, 2000.

FLETCHER, I.M.; JONES, B. The effect of different warm-up stretch protocols on 20 meter sprint performance in trained rugby union players. Journal of Strength and Conditioning Research, Champaign, v. 18, n.4, p.885-888, 2004.

FRENCH, D.N.; KRAEMER, W.J.; COOKE, C.B. Changes in dynamic exercise performance following a sequence of preconditioning isometric muscle actions. Journal of Strength and Conditioning Research, Champaign, v. 17, n.4, p.678-685, 2003.

FRY, A.C; KRAEMER, W.J. Physical performance characteristics of american collegiate football players. Journal of Applied Sports Sciences Research, Lincon, v.5, n.3, p.126-138, 1991.

GOSSEN, E.R.; SALE, D.G. Effect of postactivation potentiation on dynamic knee extension performance. European Journal of Applied Physiology, Berlin, v.83, n.6, p. 524-530, 2000. 
GOURGOULIS, V.; ANGGELOUSSIS, N.; KASIMATIS, P.; MAVROMATIS, G.; GARAS, A. Effect of a submaximal half-squats warm-up program on vertical jumping ability. Journal of Strength and Conditioning Research, Champaign, v.17, n.2, p.342-344, 2003

GRANGE, R.W.; VANDENBOOM, R.; HOUSTON, M.E. Physiological significance of myosin phosphorylation in skeletal muscle. Canadian Journal of Applied Physiology, Champaign, v. 18, n. 3 , p. 229-242, 1993

GRANGE, R.W.; VANDENBOOM, R.; XENI, J.; HOUSTON, M.E. Potentiation of in vitro concentric work in mouse fast muscle. Journal of Applied Physiology, Bethesda, v.84, n.1, p.236-243, 1998

GÜLLICH, A.; SCHMIDTBLEICHER, D. MVC-induced short-term potentiation of explosive force. New Studies in Athletics, Aachen, v.11, n.4, p.67-81, 1996.

HAMADA, T.; SALE, D.G.; MACDOUGALL, J.D. Postactivation potentiation in endurancetrained male athletes. Medicine and Science in Sports and Exercise, Madison, v.32, n.3, p.403-411, 2000.

HAMADA, T.; SALE, D.G.; MACDOUGALL, J.D.; TARNOUPOLSKY, M.A. Postactivation potentiation, fiber type, and twitch contraction time in human knee extensor muscles. Journal of Applied Physiology, Bethesda, v.88, n.6 , p.2131-2137, 2000.

Interaction of fibre type, potentiation and fatigue in human knee extensor muscles, Acta Physiologica Scandinavica, Stockholm, v.178, n.2, p. 165-173, 2003

HARRIS, G.R.; STONE, M.H.; O'BRYANT, H.; PROULX, C.M.; JOHNSON, R.L. Shortterm performance effects of high power, high force, or combined weight-training methods. Journal of Strength and Conditioning Research, Champaign, v. 14, n. 1, p. 14-20, 2000. 
HOUSTON, M.E.; GREEN, H.J.; STULL, J.T. Myosin light chain phosphorylation and isometric twitch potentiation in intact human muscle. Pflügers Archievs, Berlin, v.403, n.4, p.348-352, 1985

HRYSOMALLIS, C.; KIDGELL, D. Effect of heavy dynamic resistive exercise on acute upper-body power. Journal of Strength and Conditioning Research, Champaign, v.15, n.4, p. 426-430, 2001

HUGHES, S.; GOSSEN, E.R; SALE, D.G. Effect of postactivation potentiation on dynamic knee extension performance. Canadian Journal of Applied Physiology, Champaign, v.26, p.S486, 2001

JENSEN, R.L.; EBBEN, W.P. Kinetic Analysis of Complex Training Rest Interval Effect on Vertical Jump Performance. Journal of Strength and Conditioning Research, Champaign, v. 17, n.2, p.345-349, 2003

KANDEL, E.R.; SCHWARTZ, J.H.; JESSELL, T.M. Fundamentos da neurociência e do comportamento, Rio de janeiro, Guanabara Koogan, p.413-422, 2000.

KERRICK, W.G.; POTTER, J.D.; HOAR, P.E. Thw Apparent rate constant for the dissotiation on force generating myosin crossbridges from actin decreases during $\mathrm{Ca}^{2-}$ activation of skinned muscle fibers. Journal of Muscle Research and Cell Motility, Dordrecht, v.12, n.1, p.53-60, 1990.

KOCH, J.A; O'BRYANT, H.S.; STONE, M.E.; SANBORN, K.; PROULX, C.; HRUBY, J.; SHANNONHOUSE, E.; BOROS, R.; STONE, M.H. Effect of warm-up on the standing broad jump in trained and untrained men and women. Journal of Strength and Conditioning Research, Champaign, v. 17, n.4, p.710-714, 2003.

KOMI, P. Training of muscle strength and power: interaction of neuromotoric, hypertrophic, and mechanical factors. International Journal of Sports Medicine, New York, v.7, p.10-15, 1986. 
KRAEMER, W.J.; ADAMS, K.; CAFARELli, E.; DUDLEY, G.A.; DOOLY, C.; FEIGENBAUM, M.S.; FLECK, S.J.; FRANKLIN, B.; FRY, A.C.; HOFFMAN, J.R.; NEWTON, R.U.; POTTEIGER, J.; STONE, M.H.; RATAMES, N.A.; TRIPLETTMCBRIDE, T. American College of Sports Medicine position stand. Progression models in resistance training for healthy adults. Medicine and Science in Sports and Exercise, Madison, v.34, n.2, p.364-380, 2002.

LIEBER, R.L. e FRIDEN, J. Functional and clinical significance of skeletal muscle architectrure. Muscle \& Nerve, Hoboken, v.23, n. 11, p. 1647-1666, 2000.

LOUGHEED, K.J.; HICKS, A.L. Post activation potentiation in human dorsiflexor and plantarflexor muscles following isometric, eccentric and concentric contractions. Medicine and Science in Sports and Exercise, (supplement), Madison, v.31, p.S221, 1999.

MACINTOSH, B.R.; RASSIER, D.E. What is fatigue? Canadian Journal of Applied Physiology, Champaign, v.27, n. 1, p.42-55, 2002.

MACINTOSH, B.R.; WILLIS, J.C. Force-frequency relationship and potentiation in mammalian skeletal muscle. Journal of Applied Physiology, Bethesda, v.88, n.6, p.2088$2096,2000$.

MAHLFELD, K.; FRANKE, J.; AWISZUS, F. Postcontraction changes of muscle architecture in human quadriceps muscle. Muscle \& Nerve, Hoboken, v. 29, n.4, p. 597-600, 2004.

MOORE, R.L.; STULL, J.T. Myosin light chain phosphorylation in fast and slow skeletal muscle in situ. American Journal of Physiology, Bethesda, v.247, n.5 pt 1, p.C462-C471, 1984.

O'LEARY, D.D.; HOPE, K.; SALE, D.G. Posttetanic potentiation of human dorsiflexors. Journal of Applied Physiology, Bethesda, v.83, n.6, p.2131-2138, 1997. 
PÄÄSUKE, M.; ERELINE, J.; GAPEYEVA, H. Twitch contraction properties of plantar flexor muscles in pre- and post-pubertal boys and men. European Journal of Applied Physiology, Berlin, v.82, n.5-6, p.459-464, 2000

PLOUTZ-SNYDER, L.L.; GIAMIS, E.L. Orientation and familiarization to 1RM strength testing in old and young women. Journal of Strength and Conditioning Research, Champaign, v. 15, p.519-523., 2001.

RADCLIFFE, J.C.; RADCLIFFE, J.L. Effects of different warm-up protocols on peak power output during a single response jump task. Medicine and Science in Sports and Exercise, (supplement), Madison, v.28, p.S189, 1996.

RASSIER, D.E.; MACINTOSH, B.R. Coexistence of potentiation and fatigue in skeletal muscle. Brazilian Journal of Medical Biological Research, Ribeirão Preto, v.33, n.5, p.499508,2000

READ, M.M. The effects of varied rest interval lengths on depth jump performance. Microform Publications, University of Oregon, Eugene, Or, 1 microfiche (71 fr.): negative; $11 \times 15 \mathrm{~cm}, 1998$

SALE, D.G. Postactivation potentiation: role in human performance. Exercise and Sport Science Review, Baltimore, v.3, n.30, p.138-143, 2002

SEMMLER, J.G. Motor unit synchronization and neuromuscular performance. Exercise and Sport Science Review, Baltimore, v.30, n. 1, p.8-14, 2002

SCHMIDTBLEICHER, D. Training for power events. Em: Strength and power for sports, ed. Blackwell Scientific Publications, London, p.381-395, 1992.

SCOTT, S.L.; DOCHERTY, D. Acute effects of heavy preloading on vertical and horizontal jump performance. Journal of Strength and Conditioning Research, Champaign, v.18, n.2, p.201-205, 2004. 
SKURVYDAS, A.; ZACHOVAJEVAS, P. Is post-tetanic potentiation, low frequency fatigue (LLF) and pre-contractile depression (PCD) coexistent in intermittent isometric exercises of maximal intensity? Acta Physiologica Scandinavica, Stockholm, v.164, n.2, p.127-133, 1998

SLEIVERT, G.G.; CAMPBELL, M.G.; SALE, D.G. The effect of resistance training on postactivation potentiation of isometric twitches and dynamic voluntary movements. Medicine and Science in Sports and Exercise, (Supplement), Madison, v.31, n. 5, S327, 1999.

STEWART, D., MACALUSO, A. e DE VITO, G. The effect of an active warm-up on surface EMG and muscle performance in healthy humans. European Journal Applied Physiology, Berlin, v.89, n.6, p.509-513, 2003

SWEENEY, H.L.; STULL, J.T. Alteration of cross-bridge kinetics by myosin light chain phosphorylation in rabbit skeletal muscle: implications for regulation of actin-myosin interaction. Proceedings of the National Academy of Sciences of the United States of America, Washington, v.87, n.1, p.414-418, 1990

TESCH, P.A.; KARLSSON, J. Muscle fiber types and size in trained and untrained muscles of elite athletes. Journal of Applied Physiology, Bethesda, v.59, n.6, p. 1716-1720., 1985.

TRIMBLE, M.H.; HARP, S.S. Postexercise potentiation of the H-reflex in humans. Medicine and Science in Sports and Exercise, Madison, v.30, n.6, p.933-941, 1998.

TUBMAN, L.A.; RASSIER, D.E.; MACINTOSH, B.R. Absence of myosin light chain phosphorylation and twitch potentiation in atrophied skeletal muscle. Canadian Journal of Applied Physiology and Pharmacology, Champaign, v.74, n.6, p.723-728., 1996.

VANDENBOOM, R.; HOUSTON, M.E. Phosphorilation of myosin and twitch potentiation in fatigued skeletal muscle. Canadian Journal of Physiology and Pharmacology, Champaign, v.74, n.12, p.1315-1321, 1996 
VANDERVOORT, A.A.; QUINLAN, J.; MCCOMAS, A.J. Twitch potentiation after voluntary contraction. Experimental Neurology, Oxford, v.81, n. 1, p.141-152, 1983.

VERGARA, J.L.; RAPOPORT, S.I.; NASSAR-GENTINA, V. Fatigue and posttetanic potentiation in single muscle fibers of the frog. American Journal of Physiology, Bethesda, v.232, n.3, p.C185-C190, 1977.

VERKHOSHANSKY, Y.; SIFF, M.C. Some facts on warming up. Fitness and Sports Review International, v.28, n.2, p.64-65, 1993.

YOUNG, W.B.; BEHM, D.G. Effects of running, static stretching an practice jumps on exposive force production and jumping performance. Journal of Sports Medicine and Physical Fitness, Torino, v.43, n. 1, p.21-27, 2003.

- YOUNG, W.B.; JENNER, A.; GRIFFITHS, K. Acute enhancement of power performance from heavy load squats. Journal of Strength and Conditioning Research, Champaign, v.12, n. 2, p. $82-84,1998$. 


\section{ANEXO I - Informação pessoal e questionário de atividade física}

Nome:

Data de nascimento: Estatura: Peso corporal:

Você pratica algum tipo de treinamento de força?

$$
\operatorname{Sim}() \quad \text { Não ( ) }
$$

Se sim, há quanto tempo?

Você teve qualquer tipo de lesão no joelho/tornozelo ou algum problema neuromuscular nos últimos 6 meses? Sim ( ) Não ( )

Questionário de atividade fisica

Nos últimos 06 meses, quais das seguintes atividades você tem feito regularmente?

1- Correr pelo menos 3 vezes por semana Sim ( ) Não ( )

2- Praticado esportes como basquete, vôlei, futebol, handebol ou tênis pelo menos 2 vezes por semana Sim ( ) Não ( )

3- Pedalado pelo menos 3 vezes por semana Sim ( ) Não ( )

4- Nadado pelo menos 3 vezes por semana $\operatorname{Sim}() \quad$ Não ( )

5- Outros 


\section{ANEXO II - Consentimento Informado}

Título: "Influência da experiência em treinamento de força na potencialização da força explosiva".

Descrição do estudo: O objetivo deste estudo é verificar se a experiência em treinamento de força influi na manifestação da potencialização da força explosiva. O estudo começará com uma sessão inicial de familiarização e será completado com mais 5 sessões experimentais. $\mathrm{Na}$ sessão inicial você será orientado sobre os procedimentos do estudo. Também será avaliada a sua composição corporal e a sua força máxima dinâmica no exercício leg press. As sessões experimentais terão início uma semana após a sessão inicial de familiarização. Nestas sessões, você será avaliado no desempenho máximo do salto vertical, antes e após realizar algumas contrações isométricas máximas, no exercício "leg press". Você será testado uma ou duas vezes por semana.

Este estudo será conduzido pelo aluno de mestrado Mauro Alexandre Benites Batista da EEFEUSP. Você foi selecionado baseado na sua experiência em treinamento de força, bem como na sua permissão para avaliarmos o seu desempenho

Procedimentos: As sessões terão uma duração aproximada de 30 a 50 minutos. Você deverá manter suas atividades diárias durante o envolvimento neste estudo. Contudo, caso faça alguma atividade extenuante nas 24 horas anteriores ao teste por favor nos comunique.

\section{Riscos e desconfortos:}

1- Não existem grandes riscos envolvidos na participação deste estudo. Você poderá sentir um pouco de dor muscular nas 24-72 horas após o teste de 1RM, realizado na sessão inicial. Este desconforto será mínimo e não irá lhe impedir de prosseguir com as suas atividades diárias.

Benefícios para o sujeito: Não haverá compensação financeira pela sua participação neste estudo. Você receberá um relatório completo sobre desempenho e participação assim como do resultado final do estudo.

Nome do pesquisador, telefone e endereço: Mauro Al. B. Batista, EEFEUSP, Av. Prof. Mello Moraes 65, CEP: 05508-900, São Paulo, tel. 3818-3120/ cel: 8141-6184.

Assinaturas: Certifico que recebi completa explicação dos procedimentos, li e entendi o conteúdo deste formulário e quero participar do estudo pela minha livre e espontânea vontade. Entendo que terei o direito de me retirar do estudo a qualquer momento sem quaisquer conseqüências negativas. Em caso de publicação dos resultados somente valores numéricos e estatísticos serão liberados. Nenhuma forma de identificação pessoal será utilizada.

Assinatura do participante:

Data:

Eu, abaixo assinado certifico que proporcionei ao sujeito acima mencionado, completa explicação da proposta do estudo, seus procedimentos e todos os riscos envolvidos.

Pesquisador:

Data: 
ANEXO III - Foto do aparelho leg press

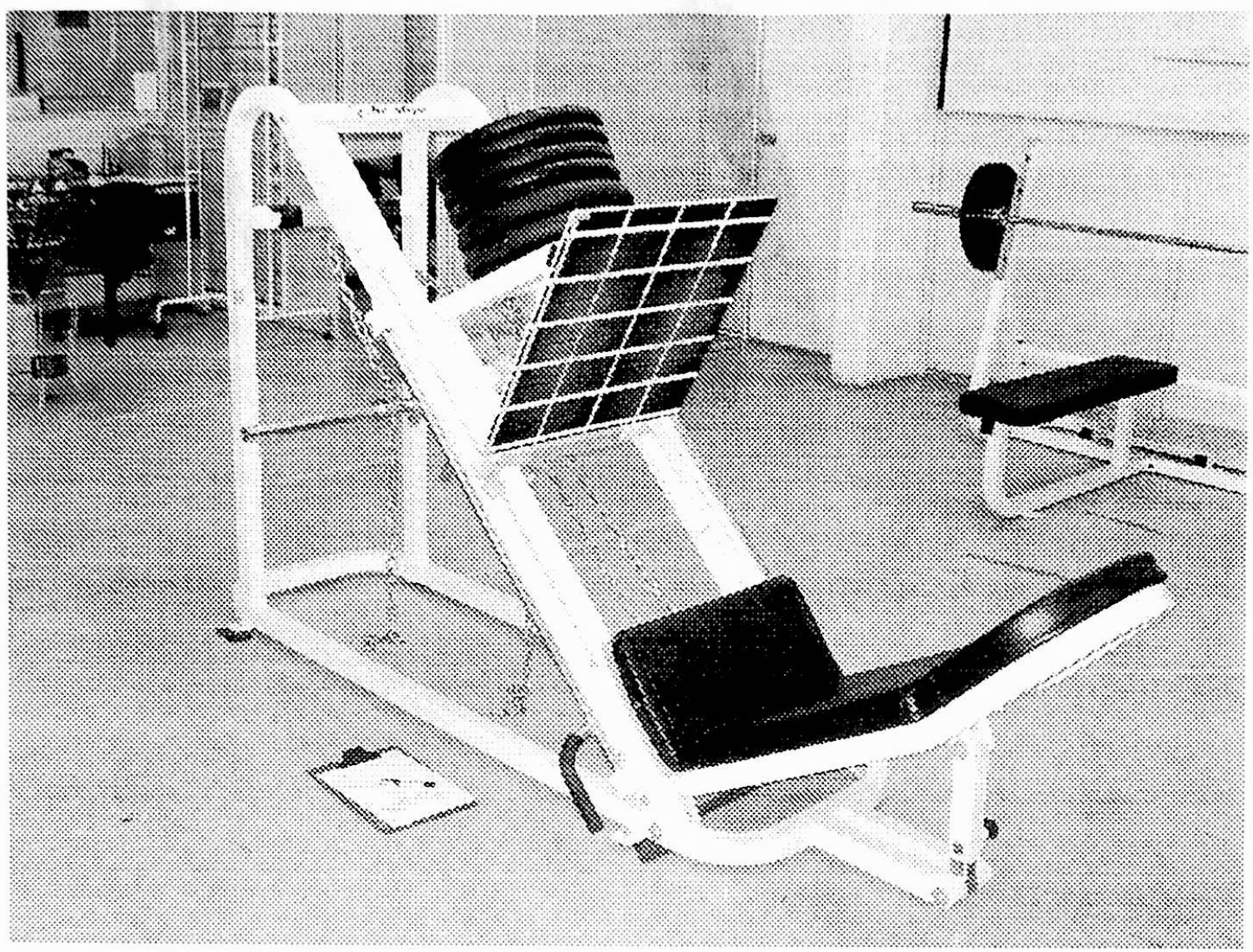

